REVEALING FOURTH YEAR NURSING STUDENTS' ASSUMPTIONS, ANTICIPATIONS AND REALIZATIONS OF LONG-TERM CARE: LEARNING THROUGH CRITICAL REFLECTION

By

\author{
Alyssa Indar \\ $\mathrm{BScN}, 2012$ \\ York University, Toronto, Canada \\ A thesis \\ presented to Ryerson University \\ in partial fulfillment of the \\ requirements for the degree of \\ Master of Nursing \\ in the Program of \\ Nursing
}

Toronto, Ontario, Canada, 2016

(C) Alyssa Indar 


\section{AUTHOR'S DECLARATION FOR ELECTRONIC SUBMISSION OF A THESIS}

I hereby declare that I am the sole author of this thesis. This is a true copy of the thesis, including any required final revisions, as accepted by my examiners.

I authorize Ryerson University to lend this thesis to other institutions or individuals for the purpose of scholarly research

I further authorize Ryerson University to reproduce this thesis by photocopying or by other means, in total or in part, at the request of other institutions or individuals for the purpose of scholarly research.

I understand that my thesis may be made electronically available to the public. 


\title{
Abstract \\ REVEALING FOURTH YEAR NURSING STUDENTS' ASSUMPTIONS, ANTICIPATIONS AND REALIZATIONS OF LONG-TERM CARE: LEARNING THROUGH CRITICAL REFLECTION
}

\author{
By \\ Alyssa Indar \\ Master of Nursing, 2016 \\ Master of Nursing Degree Program \\ Daphne Cockwell School of Nursing, Ryerson University, Toronto
}

This qualitative descriptive study explored the assumptions, anticipations and realizations of fourth year undergraduate nursing students regarding aging, gerontological nursing and LTC, as they engaged in critical reflection during their LTC placement. The use of skilled facilitation in guiding the critical reflection activities was theoretically underpinned by critical creativity (McCormack \& Titchen, 2006). The key findings indicated that the nursing student understanding during their placement experience could be described by their experiences of relationships, contextual factors and feelings. These findings may inform researchers, educators and policy-makers in enhancing the nursing student experience in the LTC setting. Furthermore, the application of critical creativity (McCormack \& Titchen, 2006) may be utilized in various contexts. 


\section{Acknowledgements}

I am deeply grateful to my thesis supervisor, Dr. Sherry Espin, for her patience, guidance and ongoing support during my journey into the world of research. I would also like to thank my thesis committee members, Dr. Karen LeGrow and Dr. Nadine Janes for their openness and willingness to fully engage in the thesis process with me. Finally, thank you to my participants for entering into this process with courage and curiosity. 


\section{TABLE OF CONTENTS}

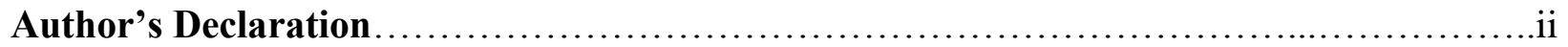

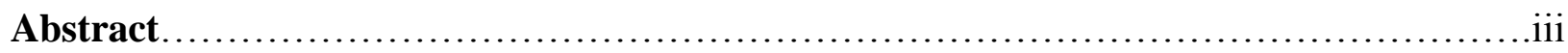

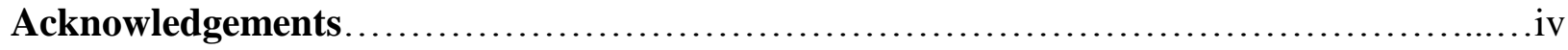

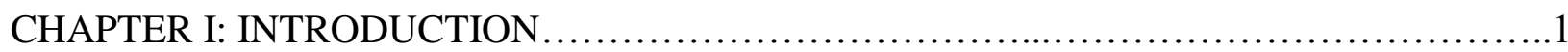

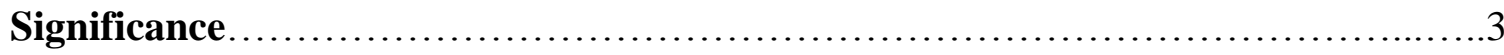

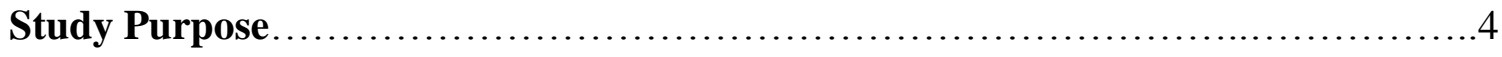

CHAPTER II: LITERATURE REVIEW .........................................5

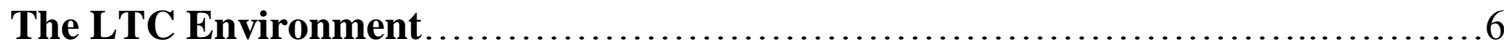

Gerontological Nursing ..................................................

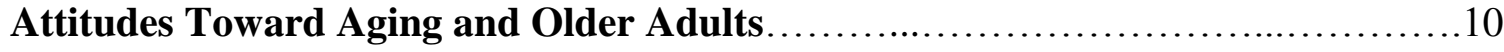

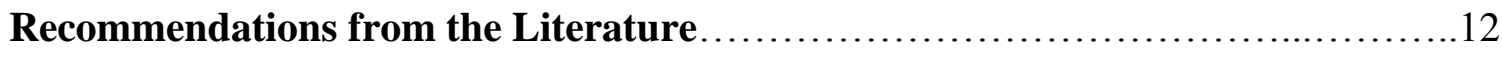

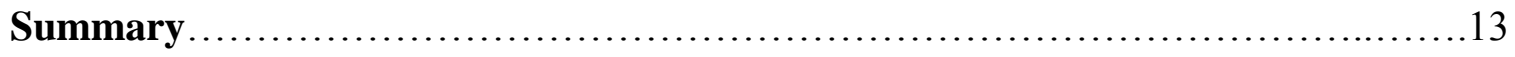

Research Questions..................................................... 14

CHAPTER III: PHILOSOPHICAL AND THEORETICAL UNDERPINNINGS ..............15

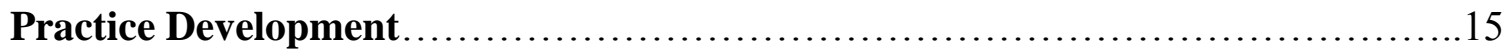

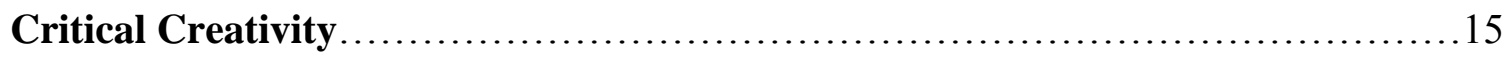

Skilled Facilitation.................................................... 17

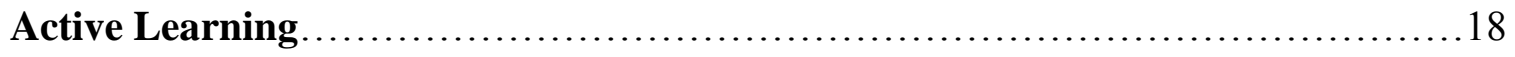

Critical Creativity Within this Study ...................................... 18

CHAPTER IV: METHODOLOGY ...............................................21

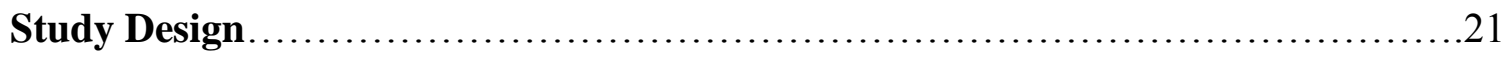

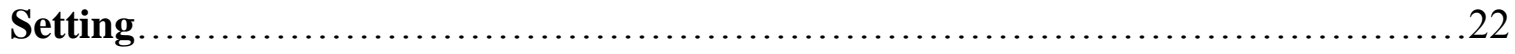


Sample............................................................... 22

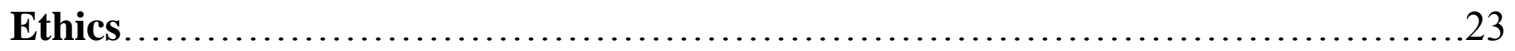

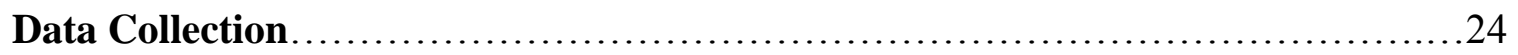

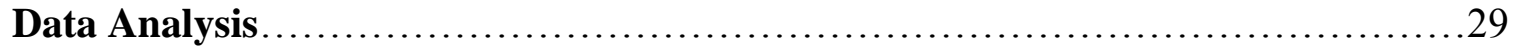

Rigour and Reflexivity ................................................ 31

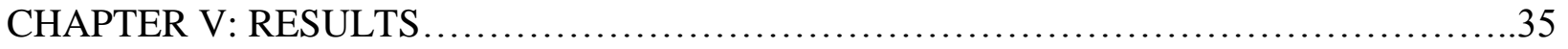

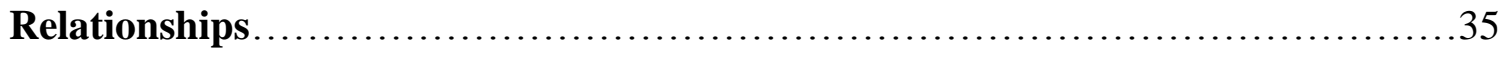

Relationships with Residents...................................... 35

Relationship with Preceptor.......................................... 39

Contextual Factors....................................................41

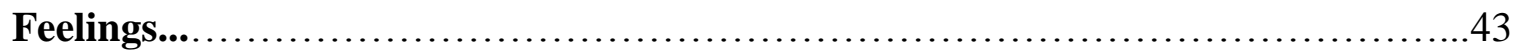

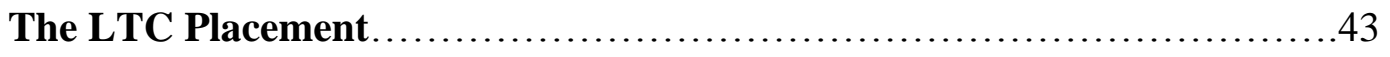

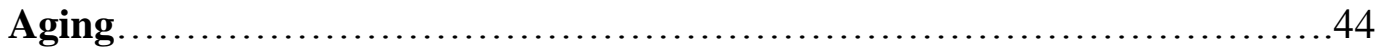

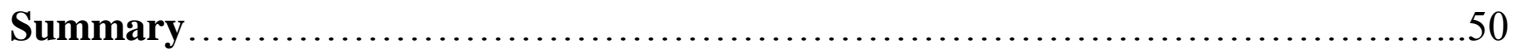

Participant Feedback on Critical Reflection Process.........................52

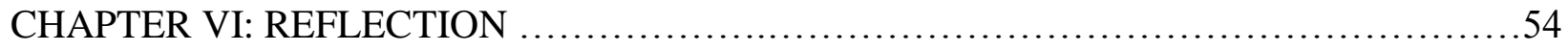

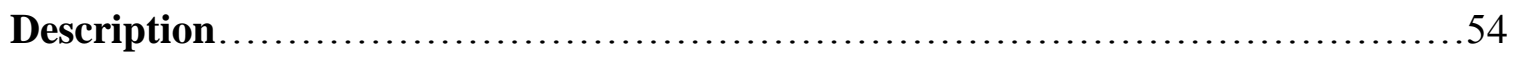

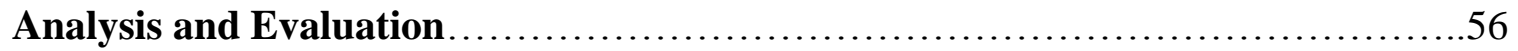

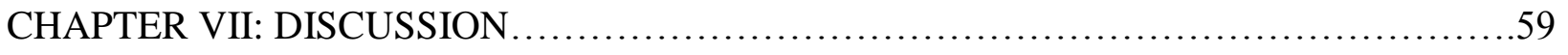

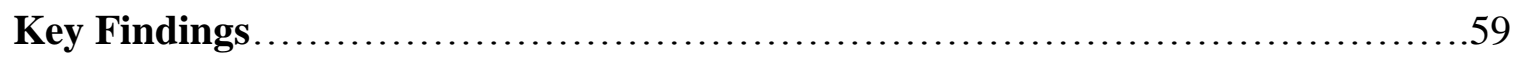

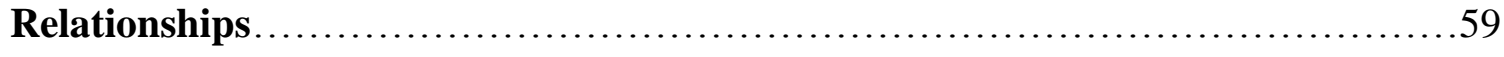

Contextual Factors....................................................62

Feelings................................................................63 


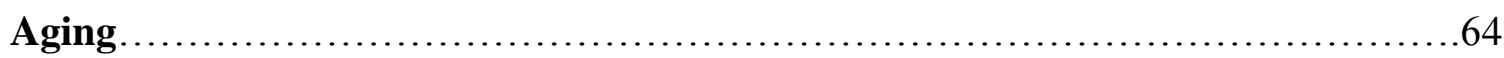

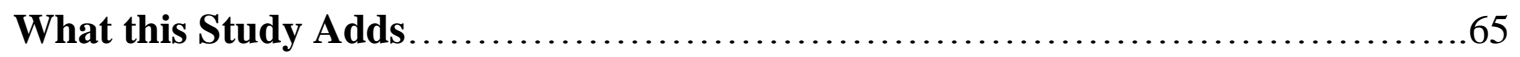

CHAPTER IX: IMPLICATIONS AND FUTURE RESEARCH.........................6

CHAPTER X: CONCLUSION ..................................................69

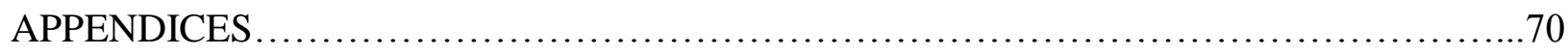

Appendix A: Recruitment Flyer....................................... 70

Appendix B: Letter to Inform Faculty of Study Purpose...................... 71

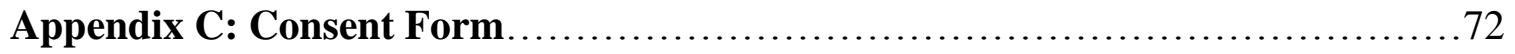

Appendix D: Critical Reflection Workshop Guides...........................77

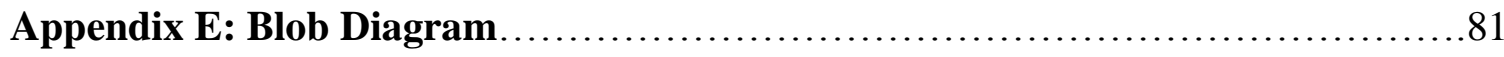

Appendix F: Example of Coding Abstraction Process........................82

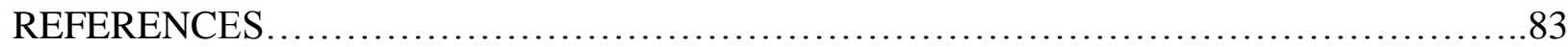




\section{Chapter I: Introduction}

Recent healthcare trends have highlighted the exponential growth of our aging population, both globally and locally. The global older adult population is expected to nearly triple by the year 2050 (United Nations, 2013). Within Canada, a quarter of the population will be over the age of 65 by the year 2051 (Statistics Canada, 2011). The Canadian healthcare system, like other systems worldwide, will need to evolve to meet the needs of our aging population. This suggests that nurses in most clinical settings will be involved in the care of older adults. It is necessary that nurses understand the unique health needs of older adults, as well as the various social, economic and contextual influences affecting their care.

New nurse knowledge of older adult care is partly informed by their experience as a nursing student in the long-term care (LTC) placement. This placement may be the first time that a nursing student learns about the health needs of older adults and the LTC environment. Often, nursing students are placed in LTC in their first year, with the intention of learning basic nursing skills related to hygiene care and assessment (Chen, Brown, Groves, \& Spezia, 2007). However, there is growing evidence to suggest that nursing students are entering a complex environment with rich opportunities for learning that extend beyond basic skills (Cammer et al., 2014).

In recent years, caring for older adults within the LTC setting has become more complicated due to increasing resident complexity (Silversides, 2011). More than three-quarters of residents require care related to a neurological disease, such as Alzheimer's disease or dementia, and more than half of residents require assistance with activities of daily living (OANHSS, 2012). Notably, the number of residents in need of complex medical care, related to oxygen therapy, drainage and feeding tubes is rising (OANHSS, 2012). As one looks beyond the resident, it becomes clear that the care of each resident is further impacted by uncertainty 
stemming from the unpredictable nature of the LTC environment (Cammer et al., 2014). The web of relationships between residents, families, nurses and unregulated care providers are impacted by various attitudes, beliefs and philosophies (Cammer et al., 2014). Contextual factors related to high patient-nurse ratios and inadequate resources further complicate resident care (Cammer et al., 2014).

Navigating the complexity of the LTC environment requires nursing students to develop the ability to critically think. Additionally, the Competencies for Entry-Level Nursing Practice (CNO, 2014) describe critical inquiry as a required skill, which supports the development of professional judgment. Ford and Profetto-McGrath (1994) describe critical thinking as encompassing the concepts of knowledge, critical reflection and action. Critical reflection therefore underpins critical thinking. The development of the ability to engage in critical reflection is an ongoing process. Typically, nursing students learn to first engage in simple reflection, in which meaning is derived from a specific past situation (Potter, Perry, \& Ross-Kerr, 2010). As the nursing student develops awareness of self and practice, the ability to critically reflect takes form.

Reflection may be likened to single-loop learning, since previous action is examined for the purpose of evaluation (Greenwood, 1998). Critical reflection relates to double-loop learning, in which the various contexts underpinning the action are explored (Greenwood, 1998). Introducing the element of criticality to the nursing student reflection process may aid students in deconstructing clinical situations and relevant contexts, as critical reflection offers a way to discover and uncover knowledge hidden within experiences (Schön, 1983; Titchen \& McCormack, 2010). Critical reflection encourages students to delve deeper, since reflections and insights are shared with others (Georges, Romme, \& van Witteloostuijn, 1999). Sharing and 
thinking collectively allows for an enhanced learning experience (Georges, et al., 1999). To grasp the critical reflective process, nursing students need opportunities within the curriculum to engage in critical reflection. This may be done in a small group, led by a teacher, as dialogue with others is crucial to the learning process (Georges, et al., 1999).

As nursing students prepare for entry into the complex environment of LTC, it may be valuable to examine how nursing education guides the student through the process of critical reflection within the context of LTC. Nursing students engaging in critical reflection will begin to deconstruct their experiences in placement and transform their thoughts and feelings into new awareness. An understanding of nursing student assumptions, anticipations and realizations during their LTC placement may assist educators in structuring the placement experience in a way that may expand learning. Furthermore, insight into the nursing student experience of LTC may aid researchers and policy-makers in addressing the learning needs of nurses in relation to the aging population.

\section{Significance}

The exponential growth of the aging Canadian population (Statistics Canada, 2011) suggests that care of older adult will become more frequent across the healthcare continuum. Nurses in a variety of clinical settings may need to expand their knowledge of older adult health needs, as well as the contextual factors affecting their care. These learning needs may be addressed in the nursing student curriculum, as students are exposed to older adults during their LTC placement. Emphasizing critical reflection during the LTC placement has the potential to aid students in examining the various contexts, attitudes and beliefs impacting older adult care. Knowledge of student assumptions, anticipations and realizations may aid researchers, educators and policy-makers in enhancing the nursing student experience in the LTC setting. 


\section{Study Purpose}

This qualitative descriptive study will describe the assumptions, anticipations and realizations of fourth year undergraduate nursing students regarding aging, gerontological nursing and LTC, as they engage in critical reflection during a LTC placement. 


\section{Chapter II: Literature Review}

A review of the literature regarding the topic of undergraduate nursing student perceptions or experiences within the context of clinical placement in LTC was completed. Literature from the past fifteen years was initially reviewed, as recent changes within the LTC sector have impacted the nursing student experience within this setting. In 2010, the Ontario provincial government changed the admission criteria for patients qualifying for LTC. As a result, current patients within the LTC setting tend to be more complex, more physically frail and require more attention due to cognitive deficits (Ontario Long Term Care Association, 2014). A search of the CINAHL database was carried out with the keywords "students, nursing" AND ("long term care" OR "nursing homes" OR "geriatrics). This yielded 17 articles. The same search was applied to the ProQuest and OVID databases, which produced 37 and 63 articles respectively. In total, the initial search produced 117 articles.

From the initial search, duplicate articles and non-English articles were removed. The abstracts of the remaining articles were carefully read and those that met the following criteria were included: (1) described the experiences and/or perceptions of undergraduate nursing students in LTC, and (2) explicitly discussed the student's perceptions and/or experiences in caring for older adults in a nursing home setting. As per the first criteria, articles examining longterm care solely from the perspectives of graduate students, staff nurses, nurse educators and other members of the interprofessional health care team were excluded. As per the second criteria, articles exploring the undergraduate nursing students' interactions with older adults in an acute or community setting were excluded. Nineteen articles in total met the stated criteria.

The references of the nineteen articles were hand searched and no date limitation was set in order to capture seminal articles. The abstracts of all articles with relevant titles that were cited 
more than once in the reference lists were reviewed. Articles that met the stated criteria were included in the literature review. The handsearching process initially yielded 43 additional articles. Upon reading each article in its entirety, it was found that a number of articles did not meet the aforementioned inclusion criteria; therefore 19 articles were excluded. The total number of articles reviewed was 43 .

Of the 43 reviewed articles there were 27 quantitative research articles, 11 qualitative research articles and five mixed method research articles. Of the research studies, 11 were conducted in the United States, ten in Australia, five in the United Kingdom, five in Norway, two in Sweden, two in Turkey and the remaining articles represented findings from Israel, the Philippines, Canada, the Netherlands, Malawi, Jordan, Greece and Taiwan. Nursing students from years one to four were represented in the literature. Four studies recruited only fourth year undergraduate nursing students (Williams, Nowak \& Scobee, 2006; de Guzman, 2009; Fox \& Wold, 1996; Ferrario, Freeman, Nellett \& Scheel, 2008).

The reviewed articles naturally divided into three content areas: (1) LTC, (2) gerontological nursing, and (3) attitudes toward aging and older adults. The final area of focus highlights key factors within the student placement experience that impact the student's perception of long-term care.

\section{The LTC Environment}

Students assigned to a long-term care placement have various responses, which are mainly informed by peers, faculty and staff (Wade \& Skinner, 2001). Some students viewed a placement in LTC as an opportunity to improve their skills related to patient-centred care and building therapeutic relationships (Lea et al., 2014; Wade \& Skinner, 2001). Other students expressed disappointment, as a LTC placement may represent a missed opportunity to learn 
'advanced' nursing skills, perceived to be more prevalent in acute environments (Abbey et al., 2006; Banning et al., 2006; Wade \& Skinner, 2001). De Guzman and colleagues (2009) described that fears related to placement often arise from faculty characterizations of long-term care as a challenging work environment.

Many studies evaluated the nursing student perception of LTC as a clinical learning environment (Berntsen \& Bjork, 2010; Brynildsen et al., 2014; Carlson \& Idvall, 2012; lvik et al., 2012). This was accomplished through the use of the CLES +T evaluation scale (Carlson \& Idvall, 2014; Skaalvik et al., 2011) and the CLEI tool (Berntsen \& Bjork, 2010; Brynildsen et al., 2014). A number of studies reported the long-term care environment to be rated as slightly positive by nursing students (Berntsen \& Bjork, 2010; Brynildsen et al., 2014; Carlson \& Idvall, 2012). However, Skaalvik and colleagues (2012) reported that students rated the long-term care much lower than acute care as a valuable clinical learning environment.

The nursing home environment scored relatively highly in the Personalization category, which contains items that describe the student's relationship with the clinical teacher (Berntsen \& Bjork, 2010; Brynildsen et al., 2014). The authors acknowledged that this may have been related to the smaller size of the nursing home settings (Skaalvik et al., 2012). In contrast, the category of Innovation was rated poorly in nursing homes, which describes novel teaching methods and activities (Berntsen \& Bjork, 2010; Brynildsen et al., 2014).

The nursing students' struggle with ongoing ethical dilemmas is well represented in the qualitative literature (de Guzman, 2009; Skaalvik et al., 2012). Students positively viewed participation in reflective processes as a strategy to deepen their learning in caring for older adults (Skaalvik et al., 2012). It was found that clinical units could not fully support reflective learning, as there was little time for reflective dialogue (Skaalvik et al., 2012). Furthermore, it 
should be emphasized that second, third and fourth year nursing students acknowledged barriers to providing patient care such as insufficient time and heavy workload (Abbey et al., 2006; de Guzman, 2009; McGarry et al., 2009). This signifies an awareness of broader systemic issues impacting the long-term care sector.

In the literature, some students having completed a LTC placement, reported the experience to be of value and left with an improved view of long-term care (Banning et al., 2006; Lea et al., 2014; Wade \& Skinner, 2001). Lea and colleagues (2014) found that nursing students left their long-term care placement feeling confident and competent in providing care for older adults. These conclusions are challenged by findings of a study conducted by Abbey and colleagues (2006). Students reported difficulties related to feeling intimidated in a nurse-led environment, managing the inferior public perception of older adult care and the perception of limited education or advancement in older adult care (Abbey et al., 2006). It should be noted that the findings of Abbey et al. (2006) represent views of second-year nursing students and clinical supervisors. Wade and Skinner (2001) also elicited feedback from nursing home staff and found many nurses to be conflicted when asked whether first-year nursing students should be exposed to the nursing home environment. Many nurses felt that first year students would not be prepared for the complexity of the setting and insisted on a specialized learning module prior to entering placement (Wade \& Skinner, 2001).

Furthermore, many studies cite the relationship between the student and his or her preceptor as crucial to the student's learning experience. In the literature, the preceptor may be referred to as the nurse mentor, clinical teacher or clinical supervisor (Carlson \& Idvall, 2012; Banning et al., 2006; Berntsen \& Bjork, 2010; Brynildsen et al., 2014; Lea et al., 2014; McGarry et al., 2009; Robinson \& Cubit, 2007; Skaalvik et al., 2010; Skaalvik et al., 2012; Wade \& 
Skinner, 2001). Positive preceptors were described by students as clinical experts, supportive of the student's learning experience and constantly securing new learning opportunities for the student (Banning et al., 2006; Lea et al., 2014). However, nearly half of the studies reported that students felt a lack of support from preceptors and clinical staff (Carlson \& Idvall, 2012; Berntsen \& Bjork, 2010; Brynildsen et al., 2014; Skaalvik et al., 2010; Skaalvik et al., 2012). Students that described negative experiences often characterized preceptors as inattentive, and the clinical unit as disorganized and ill prepared to support student learning (Brynildsen et al., 2014; Skaalvik et al., 2012). Students further elaborated that barriers related to organizational culture impeded their becoming a part of the health team (Brynildsen, 2014).

Caring for residents with dementia posed particular difficulties in the student-preceptor relationship. Robinson and Cubit (2005) found that challenges within the student-preceptor relationship were due to the preceptor's surprise at student emotions, such as fear or apprehension, when faced with providing care for residents with dementia. Notably, many students found support and enhanced their learning experience in placement through interactions with peers (Brynildsen et al., 2014; McGarry et al., 2009).

\section{Gerontological Nursing}

Regarding the nursing student interaction with residents, it was widely reported that students enjoyed building therapeutic relationships and enhancing their understanding of patientcentred care (Banning et al., 2006; McGarry et al., 2009). On the other hand, students described a number of challenges in caring for older adults such as difficulty relating to older adults, communication barriers and emotional burdens related to caring for someone who is dying (Abbey et al., 2006; de Guzman, 2009; Lea et al., 2014). Furthermore, students described the challenges of "dealing with yucky, horrible stuff all the time", in relation to providing physical 
care (Abbey et al., 2006, p. 16). Robinson and Cubit (2007) added that students with previous experience working in nursing homes reported fewer challenges when caring for residents with dementia.

\section{Attitudes Toward Aging and Older Adults}

A number of quantitative studies, in which surveys were distributed to a large number of nursing students, reported moderately positive attitudes toward older adults (Ayoglu et al., 2014; Henderson et al., 2008; McKinlay \& Cowan, 2003; Ryan \& McCauley, 2004; Zverev, 2013). These studies were representative of nursing students at all levels of education. Interestingly, two qualitative studies, using methods such as interviews and focus groups, revealed slightly negative attitudes toward older adults (Celik et al, 2010; Williams et al., 2006). Some students cited negative views of aging, as it was associated with dependence, regression, waiting for death, loss of function and disability (Celik et al., 2010; Henderson et al., 2008; Moyle, 2003). In contrast, Flood and Clark (2009) found students to have a multifaceted understanding of aging, which included descriptions of health, family and independence.

Longitudinal studies provided a more in-depth understanding of the evolution of student attitudes toward aging throughout the nursing program (Bleijenberg et al., 2012; Happell, 2002). Bleijenberg and colleagues (2012) reported a slight improvement in student attitudes toward older adults, as well as knowledge of older adult care from first to fourth year; a positive correlation was suggested between knowledge and attitude. These findings were supported by the work of King and colleagues (2013). In contrast, Happell (2002) reported that nursing student interest in working with older adults declined from first to fourth year. This suggests that nursing student attitudes toward aging and older adults should be considered as one of many factors affecting their decision to pursue work in gerontology. 
The reviewed studies originate from 11 different countries, thereby representing diverse views of aging. Many studies reference the societal views of aging as influencing the perceptions of the nursing students as it relates to their attitudes toward older adults, and intentions to work in geriatrics (Ayoglu et al., 2014; Celik et al., 2010; Hweidi \& Al-Obeisat, 2006; Lambrinou et al., 2009; Pan et al., 2009; Ryan \& McCauley, 2004; Zisberg et al., 2014; Zverev, 2013). In Turkey and Malawi, deep religious and cultural values frame older adults as sources of wisdom and depict them as respected societal figures (Ayoglu et al., 2014; Celik et al., 2010; Hweidi \& Al-Obeisat, 2006; Zverev; 2013). Within the United States, it was found that Hispanic and Latino students reported the most positive attitudes toward older adults (Ryan \& McCauley, 2004). In the cultures that viewed older adults positively, multigenerational households were a common occurrence, meaning that nursing students would often live with grandparents or other older adult kin (Ayoglu et al., 2014; Celik et al., 2010; Hweidi \& Al-Obeisat, 2006; Zisberg et al., 2014; Zverev; 2013).

Pan et al. (2010) explicitly described the impact of Taiwanese gender roles on nursing student intention to pursue a career in gerontology. Female nursing students displayed more positive attitudes toward older adults. This may be due to female socialization to take on caring roles (Lambrinou et al., 2009; Pan et al., 2010).

Zisberg et al. (2014) reported on the attitudes and knowledge levels of Jewish and Arab nursing students in Israel. It was found that Arab students scored lower than Jewish students on the attitude and knowledge surveys; however, described a higher intention to pursue work with older adults. This somewhat paradoxical finding highlights the intricate ways in which culture impacts nursing student perceptions and attitudes. Zisberg and colleagues (2014) astutely note 
that the tools widely used to measure nursing student attitudes toward older adults reflect Western concepts of aging.

Scheffler (1998), found second year nursing students to have improved attitudes following placement in long-term care. Interestingly, students with more positive attitudes toward older adults were mentored by faculty with similar positive attitudes. This is supported by the work of Hartley et al. (1995), in which first year nursing student attitudes improved postplacement. The complexity of the residents provided an opportunity for students to learn technical skills.

\section{Recommendations from the Literature}

Educational interventions including both theoretical and clinical components were found to increase student knowledge and attitudes toward older adults (Fox \& Wold, 1996; Rogan \& Wyllie, 2003; Williams et al., 2006). Two studies highlighted an increased awareness of the students to structural factors impacting care (Fox \& Wold, 1996; Williams, et al., 2006). Rogan and Wyllie (2003) reported findings related to the personal growth of students.

Interventions addressing only theoretical components of nursing curriculum produced neutral or moderately positive student attitudes toward older adults (Aday \& Campbell, 1995; Ferrario et al., 2008; Koren et al., 2008; Williams et al., 2007). Williams et al. (2007) reported improved student knowledge and attitudes as a result of context-based learning, which requires small learning groups and a faculty tutor. This learning style allowed for more interaction between students, reflection and self directed learning (Williams et al., 2007).

Many studies suggested that practice settings and academic institutions collaborate to develop models of learning that improve nursing homes as clinical learning environments (Berntsen \& Bjork, 2010; Brynildsen et al., 2014; Carlson \& Idvall, 2012; McGarry et al., 2009; 
Skaalvik et al., 2010). Collaborative models have potential to assist students by providing academic support and allowing for student feedback (Abbey, 2006; de Guzman, 2009; Robinson \& Cubit, 2007). Mentors and faculty suggested specialized learning modules focusing on care of older adults or more specifically, on care of older adults with dementia (Lea et al., 2014; Wade \& Skinner, 2001). Similarly, it was advised that mentors and educators strengthen the link between theory and practice to reduce student disillusionment and enhance learning (Banning et al., 2006; de Guzman et al., 2009). Further research is recommended to understand student perceptions of a positive learning environment and explore how nursing homes can be improved to better support nursing student learning (Skaalvik et al., 2010; Skaalvik et al., 2012).

\section{Summary}

The literature review revealed two areas for further study regarding nursing student experiences in a LTC setting. Firstly, fourth year undergraduate nursing students may benefit from placement in a LTC setting, as skills learned in previous placements facilitate higher level learning of concepts related to leadership and the complexity of care in older adults (Lane \& Hirst, 2012). Of the articles reviewed examining the experience of nursing student in long-term care, most focused exclusively or partially on the experience of first year students. There exists a scarcity of literature related to fourth year undergraduate nursing students.

Research examining the learning and socialization processes of nursing students supports further exploration of the experiences of fourth year undergraduate nursing students in a LTC setting. Reutter, Field, Campbell and Day (1997) state that first year nursing students are passive learners, focused on learning psychomotor skills and second year nursing students begin to realize the complexity of the work environment and exhibit self-centered characteristics, as they often view patients as learning opportunities. Third year nursing students are developing their 
own nursing identity as they improve their reflective and critical thinking skills and fourth year nursing students begin to think beyond the nursing student experience and become more active in learning that will prepare them for future employment (Reutter, Field, Campbell, \& Day, 1997). The insight offered by these findings suggest that third and fourth year students have developed reflective and critical thinking skills to support the complexity of a LTC setting.

Secondly, a few studies suggested that nursing students engage in reflection, as a strategy to deepen learning related to the nursing role and understanding of older adults (de Guzman, 2009; Skaalvik et al., 2012). Encouraging nursing students to build a reflexive practice is essential. However, it may be more beneficial to engage nursing students in critical reflection. The role of criticality is to deconstruct a "context, situation, crisis, contradiction or dilemma, politically, socially, historically, culturally" and reconstruct it to create new meaning (Titchen \& McCormack, 2010, p. 532). Critical reflection offers a valuable approach to both allow students to look deeply inward while expanding their awareness and understanding of the forces impacting nursing practice in long-term care. Critical reflection may be a strategy helpful in both facilitating nursing students' understanding of structural issues in practice, as well as bridging the theory-practice gap.

\section{Research Questions}

Prior to entering the LTC placement, what are fourth year undergraduate nursing students' assumptions and anticipations about aging, gerontological nursing and LTC, as revealed through critical reflection?

After completing the LTC placement, what are the fourth year undergraduate nursing students' realizations of aging, LTC and vision for gerontological nursing, as revealed through critical reflection 


\section{Chapter III: Philosophical and Theoretical Underpinnings}

\section{Practice Development}

This study is theoretically underpinned by critical creativity, which is situated within the realm of practice development (PD), thus a brief overview of PD is necessary. Practice development is a movement that promotes person-centred cultures in healthcare and education that facilitate transformation, learning and ultimately, human flourishing (Manley \& McCormack, 2003). Practice development methodology is underpinned by a number of philosophical and theoretical assumptions, which support the empowerment of individuals and teams to create contexts and cultures that support learning (Manley \& McCormack, 2003). Skilled facilitation is crucial to this process, as it allows for individuals and teams to critically reflect on values, beliefs and barriers to practice. A skilled facilitator, extensively trained in PD methodology, leads this process. The role of the facilitator is to enable individuals and teams in making explicit assumptions, values and beliefs. As the facilitator links the newly explicit knowledge to practice challenges, the individuals and teams can begin to reconstruct a healthier workplace culture. Although practice development originated in clinical healthcare contexts, many of the practice development methods may be used in an academic setting (Manley \& McCormack, 2003; McCormack, Manley, \& Titchen, 2013).

\section{Critical Creativity}

Critical creativity is situated within the broader discourse of PD, and was developed by Titchen and McCormack (2010) in response to the rigid workplace cultures existing within the dominantly biomedical healthcare environment. It is a worldview in which critical social science is brought together with creativity and ancient traditions, which espouse an appreciation for nature and beauty (Titchen \& McCormack, 2010). The intention for those who engage in critical 
creativity is to bring about human flourishing, in which the individual or group enhances their potential for growth (McCormack \& Titchen, 2006). Thus, the philosophical and theoretical assumptions of critical creativity emphasize the blending of cognition and creativity, transformation, and human flourishing.

The opportunity for transformation of the individual or culture, lies within the joining of the critical and creative aspects of an individual's self (Titchen, McCormack, Wilson \& Solman, 2011). Criticality requires the cognitive deconstruction of the layers of context encasing a situation in search of meaning or understanding (Titchen \& McCormack, 2010). The emerging insights reconstruct a new understanding of the situation (Titchen \& McCormack, 2010). The presence of creativity is crucial in both the deconstruction and reconstruction processes.

Critical reflection within this study is underpinned by critical creativity. Critical reflection is widely used and may be interpreted in various ways. Within the realm of critical creativity, critical reflection, requires the individual to use creative imagination to access embodied knowing (Titchen \& MCormack, 2010). This has the potential to allow participants to explore the knowledge hidden deep within themselves (Titchen \& McCormack, 2010).

Critical creativity is underpinned by a number of philosophical, theoretical and methodological assumptions. In viewing the philosophical assumptions of critical creativity, its' origins in critical social science are apparent, as elements such as transformative action, reflexivity and critique of false consciousness are present (Fay, 1987). However, critical creativity is distinct from critical social science, as it emphasizes the blending of assumptions, the use of creative expression in critique, transformation, person-centredness and spiritual intelligence (McCormack \& Titchen, 2006). This further underpins the theoretical assumptions of critical creativity, which highlight blending assumptions unconsciously, linking worldviews, 
human flourishing and human becoming (McCormack \& Titchen, 2006). The methodological assumptions emphasize reflective action to further blend ways of knowing and integrate creativity into practice (McCormack \& Titchen, 2006). Visualizing the multiple linkages between the philosophical and theoretical assumptions provides some clarity in understanding these rather complex elements. For example, the notion of human becoming is supported by spiritual intelligence, as a deeper understanding of one's deeply held beliefs and values are necessary to develop the whole self, including the heart and spirit (McCormack \& Titchen, 2006).

\section{Skilled Facilitation}

As previously mentioned, skilled facilitation is critical to PD methodology, as facilitators enable and empower health care teams and practitioners in creating person-centred, transformational cultures (Larsen, Maundrill, Morgan, \& Mouland, 2005). In 2001, the role of the practice development facilitator (PDF) was integrated in various practice settings within the UK for the purpose of promoting continuing professional development (Larsen et al., 2005). The legitimization of this role speaks not only to the effectiveness of skilled facilitation, but emphasizes that each PDF has a unique knowledge base and skill set, which qualifies them to work in challenging contexts. Simmons (2004) further identified that PDFs share the following attributes: "critical thinking, shared decision-making, making easier, leadership of change and equity" (Larsen et al., 2005, p. 144). PDFs adapt to the needs of the individuals and teams. Therefore, their role may encompass a number of activities, such as guiding teams in reflecting on their attitudes, values and norms or encouraging awareness regarding the need for change. (Larsen et al., 2005). 


\section{Active Learning}

From the previous role description, it is clear that the PDF does not simply deliver information to the individuals and teams, but instead engages all members in creating cultures that promote ongoing learning. This creates conditions optimal for teams to critically reflect and seek continual solutions. This method is consistent with the principles of active learning. The term, 'active learning', has been present in the literature for many years, as it was originally introduced by Chickering and Gamson (1987). Dewing (2010) has contextualized active learning within PD, and offers five fundamental principles to offer clarity. Active learning in PD requires: (1) engaging multiple senses and intelligences, (2) critical dialogue with self, (3) critical dialogue with other individuals, (4) intentional action, and (5) helping others to learn (Dewing, 2010). Looking closely at the fundamental principles, one may notice the links to double- or triple-loop learning, as critical dialogue with self and others is emphasized. The necessity to engage multiple senses offers an opportunity to infuse creative expression, which is consistent with the earlier description of critical creativity. The use of reflective action and creative expression may create opportunities in practice to integrate intentional action and facilitating the learning of others.

\section{Critical Creativity Within this Study}

Critical creativity underpins this study, as it necessary for participants to engage in creative methods in order to critically reflect on their placement experience. This is congruent with the methodological assumptions of critical creativity, as the key approach is reflective action (McCormack \& Titchen, 2006). Critical reflection has the potential to transform their understanding of aging, nursing and LTC. The exploration of participant assumptions, anticipations and realizations is facilitated by the use of creative imagination engaging multiple senses, which allows for access to embodied knowing. The critical reflection workshops rely on 
the expertise of a skilled facilitator, in order to encourage active learning through skilled facilitation techniques. Furthermore, the critical reflection workshops integrated the related concepts such as creativity and double loop learning to aid in the transformation process potentially leading to new insight and human flourishing.

Figure 1 illustrates the ways in which theory has informed this study. Critical creativity is bolded, as it is the primary theory underpinning this study. Critical creativity is a worldview that is situated within the larger discourse of practice development. PD promotes person-centred cultures in healthcare and promotes transformation, learning and human flourishing. Skilled facilitation informs critical creativity, as skilled facilitation is a methodological assumption of critical creativity. Skilled facilitation is crucial to this process, as the facilitator enables individuals and teams in making explicit assumptions, values and beliefs related to practice. The facilitator further links this knowledge to practice challenges whereby individuals and teams can begin to reconstruct a healthier workplace culture. Embedded within skilled facilitation are the principles of active learning, which emphasize engaging with multiple senses and intelligences and critical dialogue with self and others. Critical creativity requires the union of the critical and creative self. Criticality requires the cognitive deconstruction of the layers of context encasing a situation in search of meaning or understanding. The emerging insights reconstruct a new understanding of the situation. Creative imagination allows the individual to access their embodied knowing, or knowledge hidden deep within themselves. 


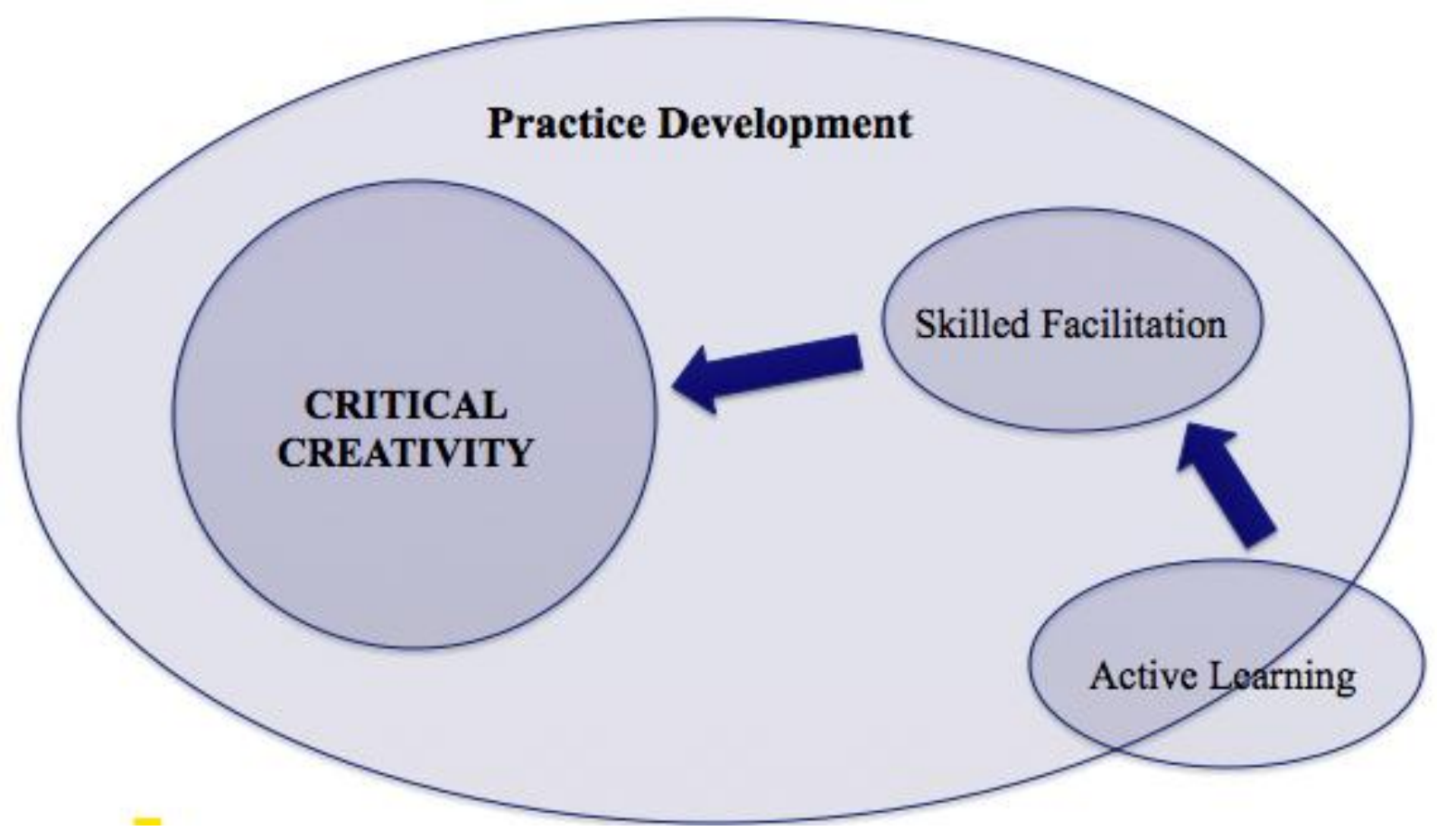

Figure 1 Theoretical Underpinnings

The philosophical, theoretical and methodological assumptions of critical creativity informed the development of the research questions and study purpose. The assumptions guided the development of the critical reflection workshops, as each activity incorporates multiple elements of critical creativity. The assumptions underpinning critical creativity have informed all aspects of this study. 


\section{Chapter IV: Methodology}

\section{Study Design}

A descriptive qualitative approach as described by Sandelowski (2000) was utilized within this study, as it supports the description of a phenomenon with regard to a selected theoretical framework. The qualitative descriptive approach may be selected when the researcher desires a description of the phenomenon, rather than a more in-depth interpretation. Similarly to other qualitative approaches, qualitative description is philosophically underpinned by naturalistic inquiry, which endeavors to study a selected subject in its most natural state (Sandelowski, 2000).

In comparison to other qualitative approaches, the qualitative descriptive design may be perceived as a more flexible method (Sandelowksi, 2000). This flexibility stems from minimal theoretical and philosophical obligations (Sandelowski, 2000; Thorne, Kirkham, \& MacDonaldEmes, 1997). Qualitative description allows for the incorporation of a guiding theory or framework to enhance the description of the selected phenomenon (Sandelowski, 2000).

The historical underpinnings of the qualitative descriptive approach may not be attributed to one individual; however, a few key researchers have advanced the understanding of the qualitative descriptive approach (Sandelowski, 2000). In 1991, Thorne problematized the issue of using qualitative approaches with strong philosophical and theoretical obligations, as it may hinder nursing inquiry. Thorne advocated for a more "generic" approach, grounded within the naturalistic paradigm to better align with the goals of nursing science and pursuit of unique nursing knowledge. Sandelowski $(2000,2010)$ has refined the notion of rigour within qualitative descriptive research, which has contributed to the legitimization of this approach. Ultimately, the qualitative descriptive approach supports the study of complex phenomena within the nursing 
discipline, as it offers researchers flexibility in incorporating a theoretical framework best suited for the particular phenomenon.

\section{Setting}

This study was conducted at one urban university, with a school of nursing, in Canada. All aspects of recruitment and data collection occurred on the university campus.

\section{Sample}

The recruited participants were fourth year undergraduate nursing students of the specified Canadian university. Purposive sampling was utilized in order to select participants that share rich descriptions of the described phenomena in relation to their LTC placement (Sandelowski, 2000). Participants met the stated inclusion criteria, in which each individual was: (a) a fourth year undergraduate nursing student enrolled at the selected university, (b) participating in a clinical placement within a LTC setting and (c) willing to participate in two four-hour group facilitation sessions. No exclusion criteria were specified.

Before beginning the recruitment process, the researcher contacted the school of nursing to seek permission in gaining access to participants. An information letter outlining key study information, as well as risks and benefits to prospective participants was e-mailed to the director, associate director and fourth year lead faculty. The researcher was provided a letter of support.

A number of strategies were utilized to recruit participants. Firstly, flyers (Appendix A) were handed out by the researcher at the fourth year nursing student orientation. Secondly, an electronic version of the flyer was posted on the fourth year undergraduate nursing student course websites (Appendix A). Prior to posting the electronic flyer, the researcher sought permission from the appropriate faculty by providing an informational letter (Appendix B). The physical and electronic flyers contained a brief synopsis of the research study purpose and 
provided potential participants with the necessary information to contact the researcher. The intention was for each critical reflection workshop to accommodate six to eight participants, as a small group allows for effective facilitation. After correspondence via university e-mail with interested participants, six individuals took part in the first critical reflection workshop. Four of the six original participants returned for the second critical reflection workshop. All aspects of the study took place on the university campus.

\section{Ethics}

This study received ethics approval from the University Research Ethics Board (REB) at the university. Informed and process consent (Appendix C) was obtained prior to engaging with participants in the research process. Process, or ongoing, consent was essential, as participants engaged in critical reflection, which has the potential to elicit strong, emotional responses. Participants were informed that they might withdraw from the study at any time and have access to appropriate counseling services.

Regarding the risks and benefits of this study, the risk to the individual participant was minimal. Potential harms may have included the elicitation of strong emotions during the critical reflection workshops. The general contact information of the university counseling services was made available on the consent form. Potential benefits of this study included new insights into the positive aspects of learning in a natural setting, the utility of selecting or creating an artifact and skilled facilitation to guide critical reflection. Participants might have found it beneficial to discuss their clinical placement experience within the critical reflection workshop, but the workshops were not intended to be therapeutic. 


\section{Data Collection}

The purpose of data collection in qualitative descriptive research is to inquire into who, what or where questions as they relate to the selected phenomena. To address these questions within this study, data was collected from two critical reflection workshops, researcher observations and field notes. Various data sources yielded rich descriptions congruent with the qualitative descriptive approach. The collection of multiple data sources strengthened the notion of rigour (Sandelowski, 1986).

Each critical reflection workshop was approximately four hours in length and each group consisted of four to six participants, excluding the expert facilitator and the observing researcher. The first critical reflection workshop occurred during the first week of the participants' LTC placements and the second critical reflection workshop took place one week after the participants' LTC placements had concluded.

Both critical reflection workshops drew on practice development methodology and active learning methods with an expert facilitator to lead the activities. As previously discussed, critical creativity promotes the blending of cognition and creativity to promote transformation and human flourishing (McCormack \& Titchen, 2006). The core principles of critical creativity informed the study design, as each activity within the critical reflection workshops incorporated critical reflection and creativity. Each activity had a distinct purpose related to the research questions and was designed to elicit feedback that would inform the subsequent activity. Prior to each workshop, the expert facilitator and researcher met to plan the activities, discuss relevant PD methods and reflect on this process.

The data collected at each workshop were transcripts of group discussions, researcher observations and field notes. The critical reflection workshop discussions were audio-recorded 
and the tapes were transcribed by the researcher. The field notes contained both observational and reflective data, documented by the researcher. The observational notes captured non-verbal participant data, such as information related to facial expressions, body language, physical interactions and sitting or standing positions. The reflective notes captured researcher thoughts and insights related to participant statements and responses. All field notes were used to reinforce, strengthen or validate participant statements. Furthermore, the researcher engaged in reflective writing for the purpose of examining personal thoughts or biases directly after each session. The guides or outlines for each critical reflection workshop may be referred to in Appendix D.

In regards to data storage, all physical data was kept in a locked office and all electronic data was stored on a password protected, encrypted USB key. All electronic data was deidentified and anonymized. Collected data will be kept for a maximum of five years.

First critical reflection workshop. The first critical reflection workshop consisted of multiple activities, each designed to address the first research question regarding student assumptions and anticipations about aging, gerontological nursing and LTC. The first activity was a group check-in, in which the participants were invited to select two Evoke cards or artifacts from a large table that reflected themselves and their thoughts about LTC. To emphasize fairness, the participant and facilitator chairs were arranged in a circle and the expert facilitator participated in all activities. The main purpose of this activity was to encourage participants to become comfortable sharing within the group, as well as to begin to uncover their assumptions about LTC. The selection of a card or artifact allowed the participant to engage in multiple senses and begin to access their embodied knowing (Titchen \& McCormack, 2010). Also, the participants were able to engage in dialogue with self, as they chose a card or artifact, followed 
by engaging in dialogue with others as they shared their insights with the group (Dewing, 2010). Hence, this activity illustrates links to critical creativity and active learning (Dewing, 2010; Titchen \& McCormack, 2010).

Next, the participants wrote their hopes and fears for LTC placement on a post-it note and pinned it to a group poster. This served to record their hopes and fears with the intention of revisiting them in the second workshop. Furthermore, the powerful action of writing a hope or fear makes explicit a thought or feeling that may have been previously inaccessible. This supports access to embodied knowing (Titchen \& McCormack, 2010).

The facilitator then engaged the participants in a guided visual reflection activity to envision their own aging. The lights were dimmed, and participants assumed comfortable positions, either sitting or lying down. Participants were asked to visualize their world as an older adult, including where they were, who was important, what their thoughts were, among other questions. Participants verbally shared aspects of their visualization journey, and then were invited to create individual art installations to depict their experience. Participants had access to a range of arts and crafts materials and worked in silence. This activity again highlights the importance of double-loop learning, in taking time to critically dialogue with self and then others (Greenwood, 1998). Expressing their visualization journey using the medium of visual art, allows for a unique opportunity in which the participants are not limited by verbal expression. In this activity, art provides another method to engage multiple senses (Dewing, 2010). The purpose of this activity, as it relates to the research question, was to explore the participant assumptions related to aging.

The participants formed pairs and dialogued with each other to convey the meaning in their art installation. Each pair chose key words that captured their thoughts, feelings and 
perceptions of aging that emerged from their critical discussion. The intention of this activity was to refine the participant views on aging. The critical dialogue allowed participants to further deconstruct their understanding and begin to link their ideas about aging to the ideas of their partner.

The keywords from each of the pairs were collected and taped to a blackboard. The entire group engaged in critical discussion to group the key words and select appropriate titles to describe each grouping. From these groupings, a shared statement of aging was created. The shared statement represented a blending of participant knowledge and linking of their ideas. Furthermore, the shared statement was the beginning of reconstructing an understanding of aging, after critical reflection or deconstruction (Titchen \& McCormack, 2006; 2010).

Next, the participants went for a walk outside to reflect on the aging statement. The thoughts collected during the nature walk were shared when the participants returned to the workshop room. The opportunity to engage in PD methods in nature has been described as stimulating and invigorating (Titchen \& McCormack, 2008). Furthermore, engaging multiple senses in a natural setting has the potential to access embodied knowing in an alternate way (Titchen \& McCormack, 2008).

Participants were then invited to choose two to three Evoke cards to represent their mantras for their LTC placement. These Evoke cards, differed from the first set because instead of featuring photographs or landscapes, each card contained a word or phrase. After reflecting on the selected cards, each participant shared their mantra with the group. This activity allowed participants to reflect on the learning that was co-created during the workshop. Sharing a mantra gave participants an opportunity to set an intention for placement that encompassed their reconstructed thoughts, beliefs and values. 
Lastly, the participants were asked to share what they liked most and least about the workshop. This provided participants an opportunity to reflect on the activities, as well as provide feedback to inform the next workshop.

Second critical reflection workshop. The second critical reflection workshop occurred a week after the student LTC placement had ended and four of the initial six participants returned. This workshop was comprised of multiple activities and the layout of the room was similar, in that the chairs were positioned in a circular arrangement. After completing a check-in activity to reacquaint the participants and prepare them for dialogue, they were invited to view the board containing the hopes and fears from the first critical reflection workshop. Each participant selected a hope and fear that was relevant to their LTC experience.

Next, each participant shared a narrative description of their LTC placement experience. In addition, the participants were asked to identify with an image Blob diagram (see Appendix E), which signified how they felt during their placement experience. The purpose of this activity was to begin to explore the second research question, regarding the student realizations of aging, LTC and gerontological nursing. Sharing a narrative, or storytelling, provided a way for the participants to share the aspects of their experience that were most meaningful. To conclude this activity, each participant shared how they felt using one word or phrase. This allowed for participants to acknowledge their feelings within the context of their placement experience.

After this discussion, participants were invited to collaboratively create a graffiti board depicting their thoughts on aging, following their placement experience. A range of magazines and art supplies were provided. The graffiti board was framed with the keywords from the first critical reflection workshop that the participants had selected to describe aging. The use of a 
graffiti board allowed for participants to engage multiple senses in reflecting on their perceptions of aging. The collaborative nature of this activity promoted critical dialogue within the group.

Following the discussion, students were asked to participate in a visioning activity, in which participants created a shared purpose of gerontological nursing. Individually, participants completed the following four statements: (1) I believe the ultimate purpose of gerontological nursing is _, (2) I believe this purpose can be achieved by _, (3) I believe the factors that help us achieve this purpose are _ and (4) I believe the factors that hinder us in achieving this purpose are _ (Warfield \& Manley, 1990). Each answer was written on a post-it note and taped to a large board containing the statements. In small groups, the participants grouped like post-its together until four general statements were formed that incorporated all of the main ideas. This signified the shift from individual statements to a collective, shared vision statement. This is further congruent with critical creativity as a shared statement promotes the blending of diverse worldviews (Titchen \& McCormack, 2006; 2010).

The workshop concluded with a stop/start/continue exercise, in which each participant was invited to share feedback regarding what should be stopped, started or continued in nursing education regarding LTC. This feedback provided valuable information regarding the participant experiences within the workshop and also the suitability of the PD methodology and active learning methods utilized.

\section{Data Analysis}

As the qualitative descriptive approach seeks to present a description of the selected phenomenon, the data analysis method most congruent with this approach is qualitative content analysis (Elo \& Kyngäs, 2008; Sandelowski, 2000, 2010). Content analysis is suitable when a low level of interpretation is required and the studied phenomenon is relatively unknown and 
multifaceted (Vaismoradi, Turunen, \& Bondas, 2013). Furthermore, the use of content analysis supports the qualitative descriptive design, as it is an iterative, constantly comparative process, in which the data is reviewed multiple times, at multiple points in the research process. This immersion ensures that the researcher stays close to the data, and provides a descriptive representation, rather than a higher-level interpretation (Sandelowski, 2000; Vaismoradi et al., 2013).

Qualitative content analysis, as described by Sandelowski $(2000,2010)$ and further elaborated on by Elo and Kyngäs (2008) was performed on the collected critical reflection workshop transcripts and field notes from the researcher observations. The process was inductive, as the researcher read and re-read the data in order to create codes that organically arise from the data (Creswell, 2013; Elo \& Kyngäs, 2008). The initial coding of the transcripts and field notes was completed independently by the researcher. Next, similar codes were grouped together to form sub-categories (Elo \& Kyngäs, 2008). From these sub-categories, the researcher engaged in the process of abstraction, in which a diagram was created to collapse subcategories into generic categories, and then generic categories into main categories (Elo \& Kyngäs, 2008). The purpose of creating main categories, is to develop phrases to describe the phenomenon (Elo \& Kyngäs, 2008). An example of the data abstraction process may be located in Appendix F. These categories were shared with the thesis committee. Each committee member conducted an independent review of the categories. This was followed by a thesis committee meeting, in which the preliminary data analysis and method were discussed. After each thesis committee meeting, the researcher would once again, immerse oneself in the data and revise the categories. The pattern of revisions and feedback from the thesis committee continued until consensus was reached by all members regarding the final main categories. The final 
analysis of the data has been presented as a scholarly, organized, descriptive summary of findings (Sandelowski, 2000).

\section{Rigour and Reflexivity}

The notion of rigour within qualitative research is complex, as it highlights the inherent tension between the artistry and science of naturalistic inquiry (Sandelowski, 1986). As interest in qualitative research has grown in recent years, a number of frameworks have emerged to evaluate rigour (Creswell, 2013; Streubert \& Carpenter, 2013). This requires the researcher to thoughtfully select a framework that will support rigour within the chosen research methodology, as each framework favours the individual qualitative approach from which it orginated (Sandelowski, 1986).

Within this study, data was collected in the form of (1) transcripts of the critical reflection workshops and (2) field notes from the researcher. The transcripts contained narratives of participant thoughts, feelings and experiences within their LTC placement. Therefore, it was logical that Sandelowski's $(1986,1993)$ conceptualization of rigour within qualitative descriptive research would guide the examination of rigour within the study for two primary reasons. Firstly Sandelowksi's (2000) approach to qualitative descriptive research has underpinned the methodology of this study. Secondly, Sandelowski's conceptualization builds on the work of Guba and Lincoln (1981), as it incorporates her expertise in examining the utility of narratives in qualitative research. The criteria described by Sandelowski to evaluate rigour were congruent with the methodology and were reflected in the data collection methods. Sandelowski's approach supports the exploration of rigour in terms of credibility, fittingness, auditability and confirmability (1986). 
Credibility is related to the pursuit of truth within the study. This is particularly complex within a naturalistic paradigm, as multiple truths are accepted (Sandelowski, 1986). Furthermore, it proposed a study is credible when the description of the phenomenon is immediately recognizable by others who have also experienced it (Sandelowski, 1986). Despite the subjectivity of the definition, there are few strategies utilized within this study to support credibility. Firstly, the researcher maintained an ongoing awareness of the researcher-participant relationships. Sandelowski (1986) elaborates that close relationships strengthen the researcher's ability to interpret that data in meaningful way, but that appropriate distance is also necessary for the researcher to acknowledge personal reflections. Within this study, closeness in the researcher-participant relationship was demonstrated by prolonged contact and the researcher presence in the critical reflection workshops. The prolonged contact aided in building trust in the researcher-participant relationship. The presence of the researcher in the critical reflection workshops allowed the researcher to experience the atmosphere created by the participant narratives. This data was captured in the field notes as descriptions of participant non-verbal behaviour. In contrast, the researcher maintained an appropriate distance from participants by acknowledging on personal reflections throughout the research study in reflective field notes and reflective memos. Secondly, data was collected in the form of audio-taped transcripts of the critical reflection workshops and field notes. The audio recordings and field notes were transcribed by the researcher. Relying on multiple sources of data strengthens credibility, as the field note descriptions clarified, supported and enhanced the transcript data.

The definition of fittingness is understood in two ways: (1) the degree to which the study findings are meaningful in other contexts and (2) the degree to which the findings represent the data (Sandelowski, 1986). In regards to the former definition, the data within this study is highly 
contextualized, as naturalistic inquiry does not seek to understand how the phenomenon is experienced within the specified context (Sandelowski, 2000). However, the meaning distilled from the data, through data analysis, may resonate with diverse groups. The latter definition emphasizes rigour within the data analysis process. The fittingness of the data was enhanced by multiple rounds of analysis with an expert thesis committee. Critical dialogue within the analytical meetings was useful, as various aspects of the analysis were continually challenged.

Auditability is achieved by providing detailed description of the research methods in a way that the reader clearly understands the decisions made by the researcher. Furthermore, a researcher replicating the methods, would find 'comparable' findings (Sandelowski, 1986). It is important to note that the findings may not be too similar, as qualitative research favours exploration, rather than confirmation. Within this study, the methodology and appropriate rationale were richly described. For example, another research may use the described methods to apply a critical reflection workshop in an alternate setting or with other participant groups. The potential findings may not be similar to those in this study, but depth of the participant reflection may be comparable.

Confirmability relates to the meaningfulness of the study findings, often by embracing the subjectivity and is present when the first three criteria have been met (Sandelowski, 1986). Similarly to credibility, closeness in the researcher-participant relationships is desired, as it facilitates researcher engagement with the data. The strategies contributing to the enhancement of the credibility, fittingness and auditability have been described in detail above.

In regards to rigour, reflexivity has been demonstrated throughout the research process by the description of processes such as reflexive journaling, recording reflective field notes and debriefing with the thesis committee members. These strategies are helpful when engaging in 
research underpinned by naturalistic inquiry, as reflexivity enhances the exploration of complex, subjective phenomena (Creswell, 2013; Streubert \& Carpenter, 2011).

As this study took place on the university campus with undergraduate students, special considerations were made to address issues of power during workshops with participants. The facilitator established trust with participants, by engaging them in a number of activities related to practice development methodology. Furthermore, the facilitator was aware of verbal and nonverbal communication that may have revealed an unequal power dynamic. The researcher assured participants orally and verbally in the consent forms, that their choice to participate in the research study would have no academic consequence. 


\section{Chapter V: Results}

Sandelowski (2000, 2010) specifies that qualitative content analysis seeks to describe, rather than interpret the selected phenomenon. From the data analysis of the transcripts and field notes, emerged three main categories: (1) relationships, (2) contextual factors, and (3) feelings.

\section{Relationships}

The participants described two primary relationships that impacted their understanding of LTC: (1) the relationships with the residents, and (2) the relationship with their preceptor.

Relationships with residents. The emphasis on building relationships with the residents was present from the first critical reflection workshop, when one participant identified:

Long-term care is unique in itself because I think it's easier to form relationships with your patients. And then you have this ability to see them as this unique person because you are there for such a long period of time that maybe you have a bit more time to get to know the person, who they are, and I think that that's super important for nursing. (Critical Reflection Workshop 1, Participant 5, 74-78)

From this initial statement, participants examined their perceptions of residents in the LTC setting. To facilitate this, participants were asked to choose an Evoke card or artifact that resonated with their perception of LTC and share their understanding with the group. The nature of the activity allowed for many of the perceptions to be articulated metaphorically. The following quotes emphasize how the resident is perceived in LTC.

And then this cat [Evoke card] I took to represent what I think of long-term care a lot of times. Not all the time. But it's kind of like a dark picture and the cat looks kind of sad and stuff. And I don't know, I just imagined what I see in long-term care sometimes is like how people treat a pet. I'll do the necessities for you and then I'm going to leave you alone. And a lot of times, I feel like that's what I see in long-term care or in different settings like that. And they're just really lonely. (Critical Reflection Workshop 1, Participant 3, 46-51)

And I think that's also represented in nursing homes, where like in the beginning of nursing where people are lonely and are just like left to rot. Sort of like with people with Alzheimer's, they don 't...they don't look at the potential that's there, even though they have a disease. (Critical Reflection Workshop 1, Participant 5, 426-428) 


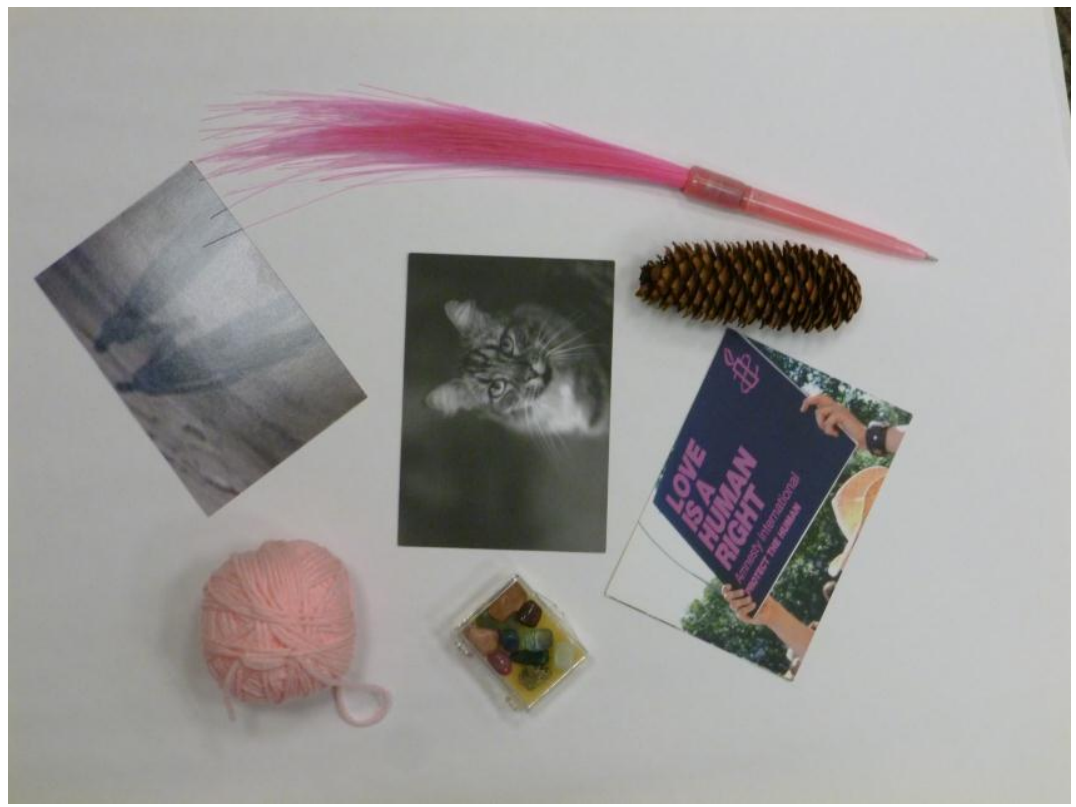

Figure 2 Selected Evoke cards and artifacts

The powerful insights gleaned from these quotes illustrate the way in which care of residents is perceived. It should be noted that these perceptions were present prior to the participant placement in LTC. From this profound dialogue, participants then reflected on their intentions for placement. To facilitate the reflection on intention, participants were encouraged to select two to three Evoke cards to share with the group. Below are quotes from two of the six participants, detailing their intentions or mantras for their gerontological nursing practice.

I picked imagination first because I think when working with older adults...you know, after doing all of these activities, I think you need to imagine what their life was like before and think about their journey and how they see their life and you can't just assume. It could be different from what you perspective is and I guess that relates to second one, support. So, that means listening to them, listening to their story, understanding them and understanding that this phase in their life is really hard for them. And we need to support them as nurses. Yeah we do our skills all the time, but we need to support them as well emotionally. So that's my takeaway message for practice this semester. (Critical Reflection Workshop 1, Participant 6, 461-468) 
This is one is shine, the shine card. I just want to be someone that can lift people's spirits. I know that long-term care can king of be a depressing place to be. Like even just by smiling or greeting people, asking them how they are can be like a light to them, a sort of joy, pleasure, things like that. My second card is the connection card. I want to remember throughout my placement that it's not just the skills and practical stuff, but also the relationships you form with each resident, and yeah. And the final one is tenderness. I'm on a floor that houses residents with Alzheimer's and dementia.... So I just have to be like patient and tender, and not take offense to things or like protect myself. I don't know if you guys know about gentle persuasive approaches. Yeah, I did that and I learned a lot about how to deal with people with dementia and stuff. And just keeping in mind that it's not necessarily them, it's just the disease. (Critical Reflection Workshop 1, Participant 1, 477-489)

The inclusion of quotes from the participants was important to illustrate the overwhelming positivity and hope embodied in each of the sentiments. To summarize, the key words in the mantras created by the participants were: imagination, support, shine, connection, tenderness, empower, mindfulness, beauty, listening, partnership, independence, opportunity, friendship, love, creativity and reflection.

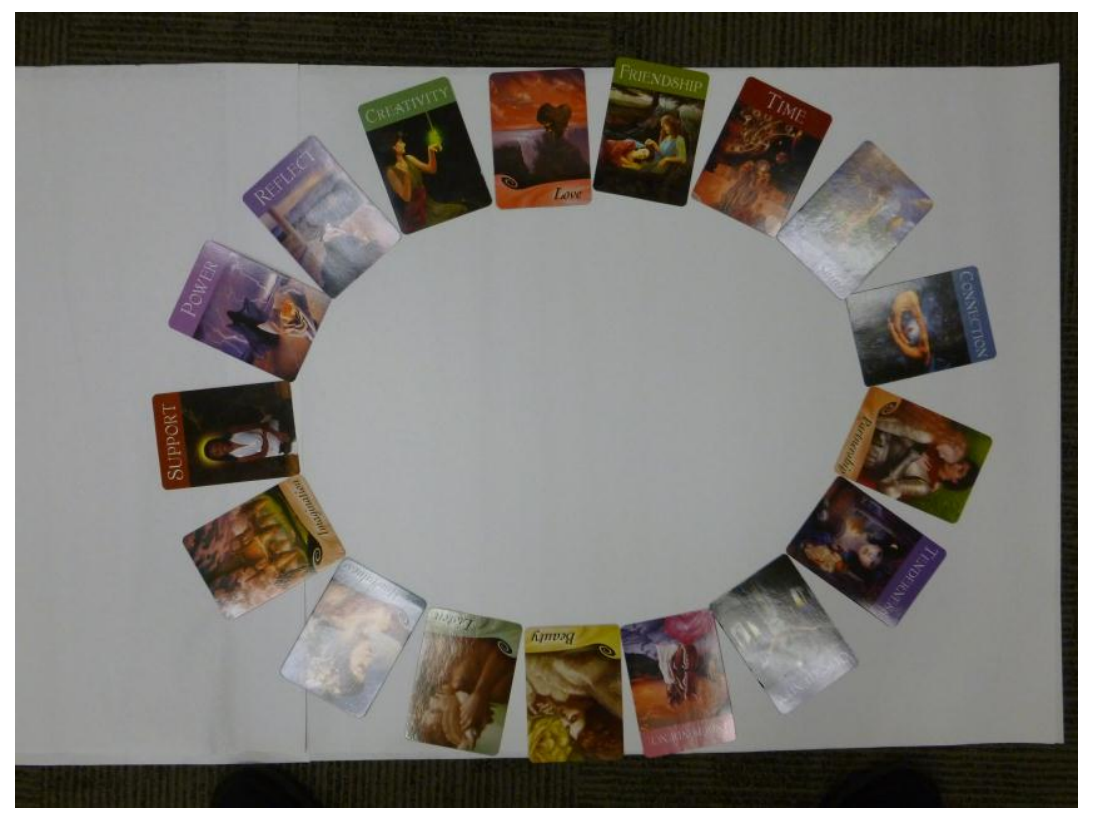

Figure 2 Selected Evoke cards summarizing mantras for nursing practice

In the second critical reflection workshop, participants described the importance of cultivating relationships with residents. The following participant describes her experience: 
There was this one specific resident...I like love her. [Laughs.] She told me a lot about her experiences growing up and stuff. And that was a hope that was accomplished, to actually be able to have a relationship with the residents. (Critical Reflection Workshop 2, Participant 1, 340-343)

Participants implemented strategies for building relationships with residents. The following quote highlights intentions related to friendship and connection:

When I was not doing meds or whatever I would just go into the TV room and like sit with them. There was a lot of free time I'll admit, but I'd just go into the TV room with them and sit, talk with them, create that relationship with them, laugh with them. (Critical Reflection Workshop 2, Participant 1, 326-330)

Although participants entered their LTC placement with the intention of building relationships with residents, all participants expressed difficulty in finding the time to talk with residents. This was further complicated by the difficulty encountered in communicating with residents living with a cognitive impairment, such as dementia or Alzheimer's disease. The following quotes illustrate the dilemmas described by the participants.

You still feel guilty about it because you're like, man I wish that I could just like talk to this patient, you know. People are just like screaming out for things. When people have dementia, you can address the issue but it will still be an issue. Like if its' an issue, it's an issue, you know what I mean? Sometimes you need to just tune them out, which is so horrible, because these people just keep saying the same thing over and over again. Do you know what I mean? If you go over and talk to them like half an hour later, they're still going to be doing the same thing. So it's like, what do you do then? (Critical Reflection Workshop 2, Participant 5, 241-248)

There were a lot of patients that became aggressive, especially dementia patients. So learning to deal with that. Not having abrupt gestures when you're like trying to give them medication, talking to them slowly. I don't know, I guess you figure that out as you go. And then being in charge of 25 plus patients, so we had 32 on our floor. (Critical Reflection Workshop 2, Participant 5, 267-270)

The demands of managing many, complex residents is evident. Participants further elaborated on the complexity of each resident, when understanding the role of family. One participant described family members as key to understanding how to care for the resident. 
You really can't just look at a person in their isolated state as they are now. You have to take the whole picture in. You really have to talk to the families. (Critical Reflection Workshop 2, Participant 3, 771-778)

Another participant described her experience, when realizing that each resident's relationship with their respective family is unique and characterized by long, complicated histories.

I was surprised to see how many family members didn't come visit their family members. And I did a lot of research about Alzheimer's and dementia for my learning plan and a topic that kept coming up was family-centred care and also patient-centred care. And that you need to know more about the families to provide patient-centred care because the longer the time the patient can't speak up for themselves, they can't advocate for themselves. Yeah, so your story for example with that family and you talked to them, and got to know them, their background and their story... I found that when I did get the chance to talk to family members, which was not very often, I got to know a lot more about the patient. And I just think it's sad and I need to like refrain from like making judgments about why the families aren't coming to visit. (Critical Reflection Workshop 2, Participant 5, 846-854)

The participant understanding of residents in LTC evolved throughout the course of this study. In the first critical reflection workshop, participants examined their perceptions of residents and used the new perspectives to inform the creation of their mantra to guide their gerontological nursing practice. Within the second critical reflection workshop participants shared the value of building relationships with residents, but also revealed challenges related to communication within the context of cognitive impairment. Participants further identified the complexity of the resident relationship with his or her family.

Relationship with preceptor. The relationship between participant and preceptor was described as critical to the participant learning experience in placement. Participants describe that the preceptor often sets the tone for the placement experience:

In the beginning I was really excited because everyone seemed really nice there. But then later on I felt that the environment was different. And it had to do a lot with my preceptor and the director of care. (Critical Reflection Workshop 2, Participant 6, 390-392) 
And when I went in and had my orientation and just met my preceptor, the first thing she told me was, oh it's going to be tough for you. That's all, we didn't even talk that much. She told me, are you sure you want to do this? And then I was like yes definitely. (Critical Reflection Workshop 1, Participant 4, 579-586)

The preceptor not only role models the gerontological nursing role, but also facilitates learning opportunities for nursing students. Tensions were evident when participants felt unsupported.

I think that the conclusion that I came to was that your experience has so much to do with the people that are like supporting your learning, and I think that maybe my preceptor could have supported my learning like a little bit better. As much as it was great that she gave me so much responsibility, like I didn't feel that vibe where it was like, okay we want to make things better and we want to progress. There were questions that I would ask and she would just be like, oh we just do it that way. And I was like, well why aren't we doing that skin assessment? Isn't that what we're supposed to be doing? She would be like, oh they're good, they're find. And you're like this isn't thorough, this isn't like you know? So that kind of frustrated me but... (Critical Reflection Workshop 2, Participant 5, 174-181)

Participants described instances when the preceptor's expectations were incongruent with

the participant's perceived capabilities.

But I think that communication is like the biggest thing. She didn't explain things very well so I kind of just had to figure things out on my own. I was like how do I this dressing? And she was like you just do this, this, this and this. And I'd be like okay. And I'd be like I'll just figure it out. (Critical Reflection Workshop 2, Participant 5, 257-263)

The first few weeks I was there, she would do the medications with me. She would get kind of frustrated because it was taking too much time to do that. And she would make it very known that she was getting frustrated with me for like taking too much time. And the other thing that she got very frustrated with was if she felt that I was doing something that was beneath me as a nurse. Like if I had time, a couple times she'd be helping me with the meds or if someone else was there, I could help the PSWs out, because they're very busy... go to the washroom with this patient. She'd be like no, medications [claps hands]. That's not your job. That's not your job. I was like okay, but I can support them though. (Critical Reflection Workshop 2, Participant 3, 641-648)

The frustration described by participants stemming from the lack of preceptor support

limited the participant ability to connect nursing theory and practice. Participants expressed the difficulty of enacting nursing theory within a setting impacted by multiple contextual factors, 
which will be elaborated on further. The following quote emphasizes the challenges in applying

nursing theory to a real-life context.

And so that kind of frustrated me and I think that's like a frustration that goes across all fields of nursing because you don't have the time to be this nurse that you have imagined yourself to be. As a student nurse, we're given these expectations and there's so much emphasis on school and personal performance. And then you get to your placement and nobody tells you in school, hey there's all these different factors that affect the nursing you provide. Like staffing and workload and all these different things. And it's like you king of put it on yourself. Like, my personal performance isn't up to par and I need to be better and I need to somehow... But then you realize, no there's all these other factors that I don't have control over, and I can't blame myself for that, you know? I think that's a realization that I came to as well. (Critical Reflection Workshop 2, Participant 5, 200209)

\section{Contextual Factors}

In the first critical reflection workshop, participants expressed their perceptions of the LTC environment. The following quote presents a metaphor facilitated by the selection of an artifact (see Figure 2).

I chose a pinecone to represent the general perception of long-term care. Pinecones are unappealing, No one really wants to take it up. (Critical Reflection Workshop 1, Participant 1, 23-25)

Another participant described how her perception of the LTC setting was informed by a

previous community placement.

My placement last year was at CCAC, and...my preceptor was a case manager, and she worked with people who worked in long-term care, sorry, people in residential retirement homes, and subsidized living. Those people, along with people in long-term care are constantly seeking home visiting services and it's just never enough. And the staff, it's just understaffed. I'm not saying, it's not anything against any staff that works in longterm care. If you don't have the time, you don't have the time. You can't sit with people all the time. (Critical Reflection Workshop 1, Participant 3, 53-59)

The realization of the impact of contextual factors on gerontological nursing practice was much more present in the second workshop, after the participants had experienced the LTC placement. Participants expressed a lack of time in providing patient care, especially due to the large $\mathrm{RN}$ to patient ratio. 
The only thing she really taught me was how to do wound care because we had a lot of wounds on our floor and there was only one RN for the whole nursing home and there were like 100 patients. And there were two RPNs per floor. There were two floors. And there were like five PSWs for each floor. But sometimes they were short so there would be like three or four PSWs for each floor and each floor had 42 residents. [In the background, someone says 'wow'] It was hard. It was very busy there. (Critical Reflection Workshop 2, Participant 6, 401-407)

I was so dissatisfied. I kind of felt powerless there or isolated there a lot of the time. It was hard. If I was really busy doing all of the meds, it would be super stressful for an hour giving out the meds. And they wanted something, it was like, oh I don't have time to like talk to you. (Critical Reflection Workshop 2, Participant 3, 738-747)

Participants also felt limited by the social structure of the nursing homes, as the presence

of hierarchy often hindered communication and teamwork.

The way that the higher people, like the DOC [director of care] and RN treated the other workers, like the PSWs and RPNs, like it wasn't very nice. They didn't have a good relationship, so things were just tense and nothing would get done the way it should be. And communication was just not there. I experienced that too. Like in the beginning I thought it was good but then when I really got into it, like the structure made everything not work. Like I saw a lot of things that could have been improved on, but as a student I can't...like I feel not in a place to do that. (Critical Reflection Workshop 2, Participant 6, 407-414)

And the other thing that she got very frustrated with was if she felt that I was doing something that was beneath me as a nurse. Like if I had time, a couple times she'd be helping me with the meds or if someone else was there, I could help the PSWs out, because they're very busy...go to the washroom with this patient. She'd be like no, medications [claps hands]. That's not your job. That's not your job. I was like okay, but I can support them though. (Critical Reflection Workshop 2, Participant 3, 644-649)

Contextual factors such as lack of time, heavy workload and social structure impacted all aspects of the participant experience in their LTC placement. As previously described, participants felt that a number of contextual factors affected their relationships with residents, as well as their relationship with their preceptor. 


\section{Feelings}

The participants described their feelings related to: (1) their LTC placement and (2) aging.

The LTC placement. The critical reflection workshops incorporated a number of activities, which required the participants to take note of their thoughts and feelings. Thus, rich descriptions of participant feelings were present throughout the data.

The participants in the first critical reflection workshop described feelings of anticipation related to the opportunities associated with the LTC placement. Notably, the critical reflection activities enabled the participants to articulate their feelings in the form of creative metaphors. The following participant describes her experience in choosing an artifact (see Figure 2) to depict her anticipation for her LTC placement:

I picked the ball of yarn to signify my perceptions of long-term care because this was me in the beginning. A ball, kind of really anxious...could not sleep for two weeks, but after going to orientation and getting to meet my preceptor, I was able to loosen up a bit. I got excited for opportunities that I'll have, so it's sort of like unraveling the yarn and hopefully making something beautiful out of it. (Critical Reflection Workshop 1, Participant 2, 33-37)

The second critical reflection workshop revealed that participants experienced a range of feelings during their LTC placement. Each participant shared a narrative of their LTC experience, and described feelings of frustration, guilt, anger and pride. When asked to choose a figure on the Blob diagram (Appendix E) to represent how they felt during placement, a few participants responded:

At some point I've been every blob on this page. (Critical Reflection Workshop 2, Participant 3, 112-113)

It's so difficult for me to choose a specific blob because I feel like I have experienced all of these things during my placement and any of these things. (Critical Reflection Workshop 2, Participant 5, 118-119) 
The participant narratives of their LTC placement reveal moments of frustration, as well as moments of pride, as characterized by the following quotes.

That was a really frustrating shift because I just wanted to be like, hey I kind of like know some of these things. I don't appreciate you giving me some of this feedback. So like that would have been the angry person [blob diagram]. That was also another 16-hour day so after I took a break to eat, I came back with a completely new perspective, but the beginning of that day was really frustrating for me though. (Critical Reflection Workshop 2, Participant 5, 162-166)

I felt kind of solid. Like the first time I did all of the medication by myself and felt really good about it. But like I still felt like I had done it on my own. Which is fine because part of me has to learn to be a better independent learner, in some regards. So that was a good experience in that way. Anyway that was my experience. (Critical Reflection Workshop 2, Participant 3, 780-783)

After the participants had shared their detailed experiences of the LTC placement with the larger group, each participant was asked to sum up how they felt with one word. The participants selected the following key words: "complicated", "heavy", "similar" and “challenging" (Critical Reflection Workshop 2, 788-793)

The emotional journey described by the participants reveals that initial positive anticipations and general perceptions evolved into more complicated feelings. The LTC experience coupled with critical reflection revealed a new perspective in which participants were able to understand that elements of the LTC setting are neither good nor bad. Instead, each element is complex and affected by a web of interacting relationships and contextual factors.

Aging. To understand the participants' initial thoughts and feelings associated with aging, a number of critical reflection activities were utilized in the first workshop. Participants took part in a visualization exercise, in which they envisioned their own aging journey. The insights from this activity were shared with the larger group and then translated into individual art installations (see Figures 4 to 9). In pairs, the participants discussed their art installations and 
helped each other choose key words that characterized their thoughts about aging. The key words were shared and the group collectively grouped similar words together. This resulted in a collective definition of aging, which incorporated the following key words and phrases: connections, growth, reflecting on the journey, peace and achievements.

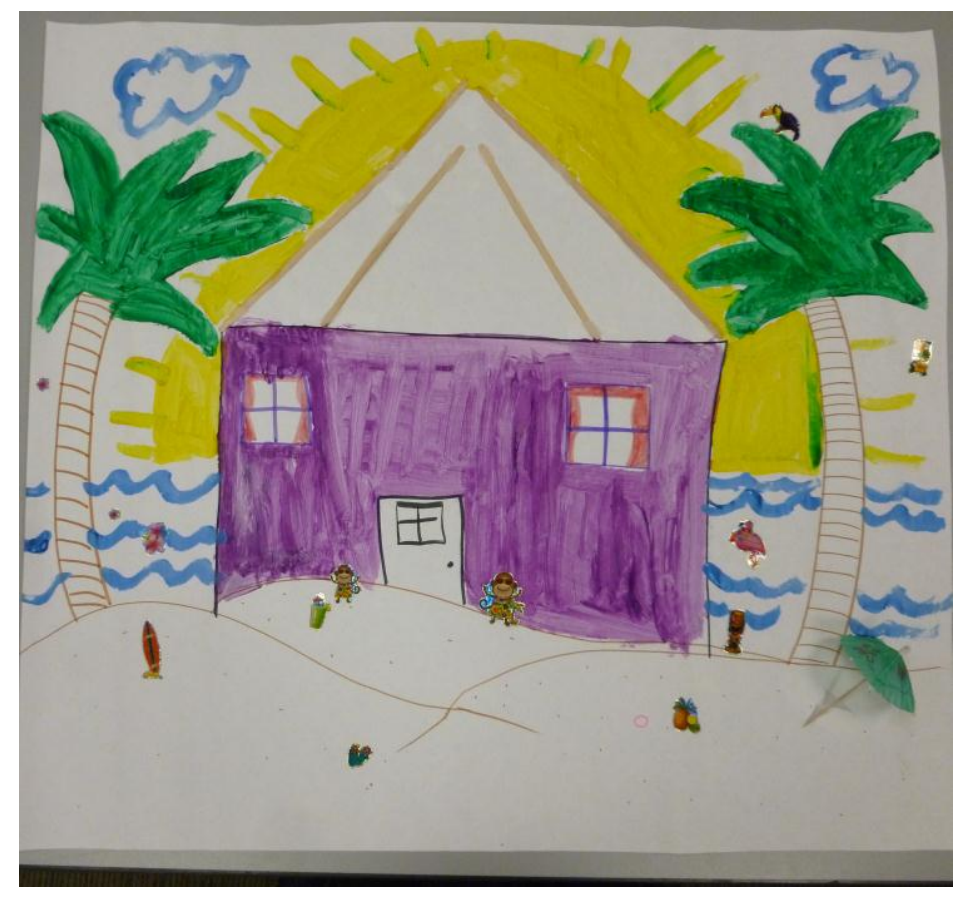

Figure 4 Participant Art Installation 


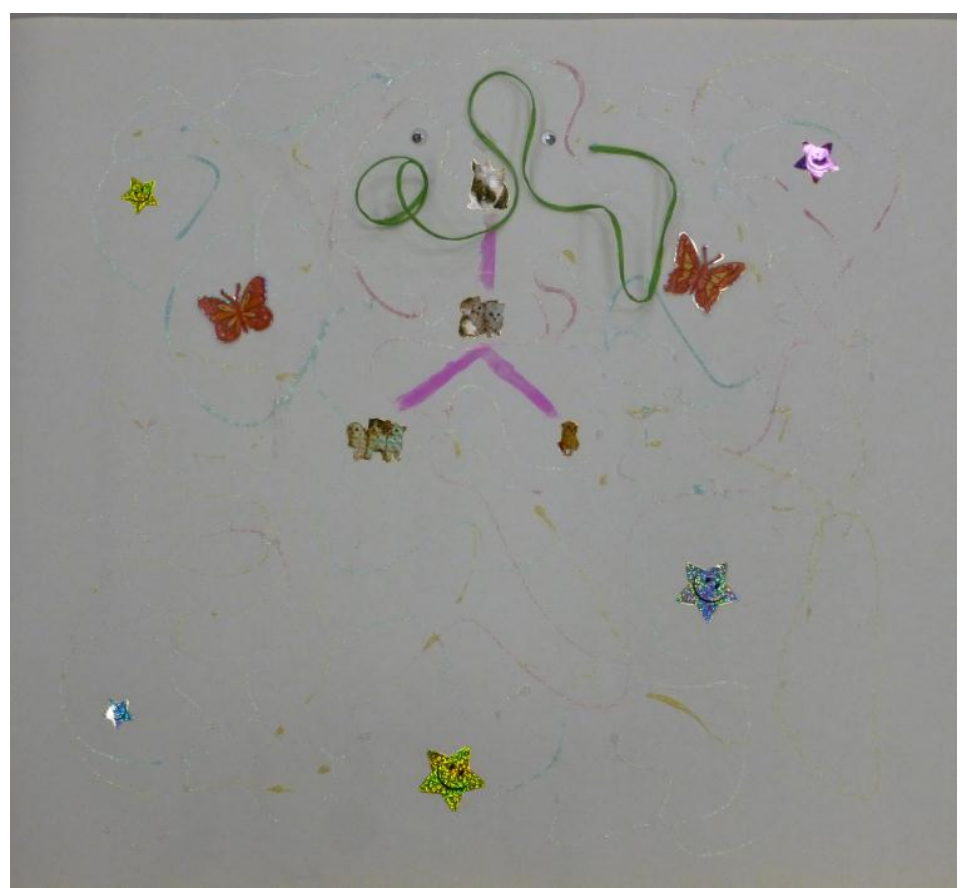

Figure 3 Participant Art Installation

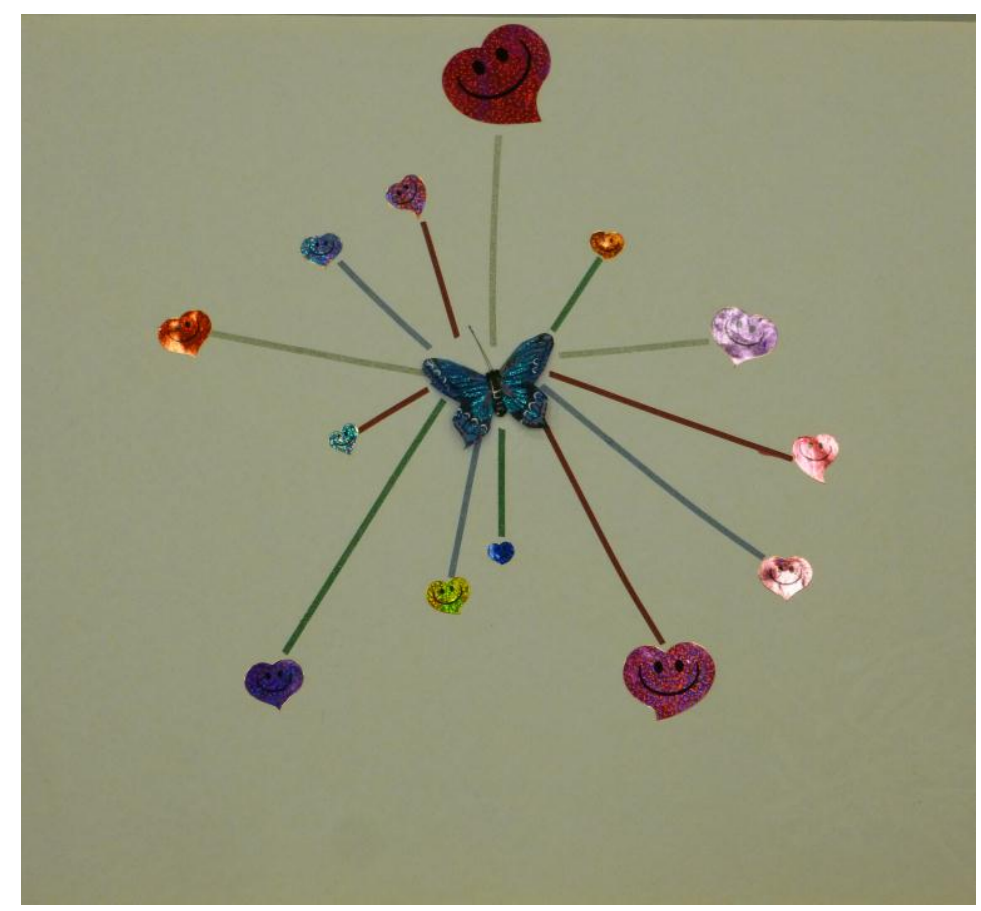

Figure 4 Participant Art Installation 


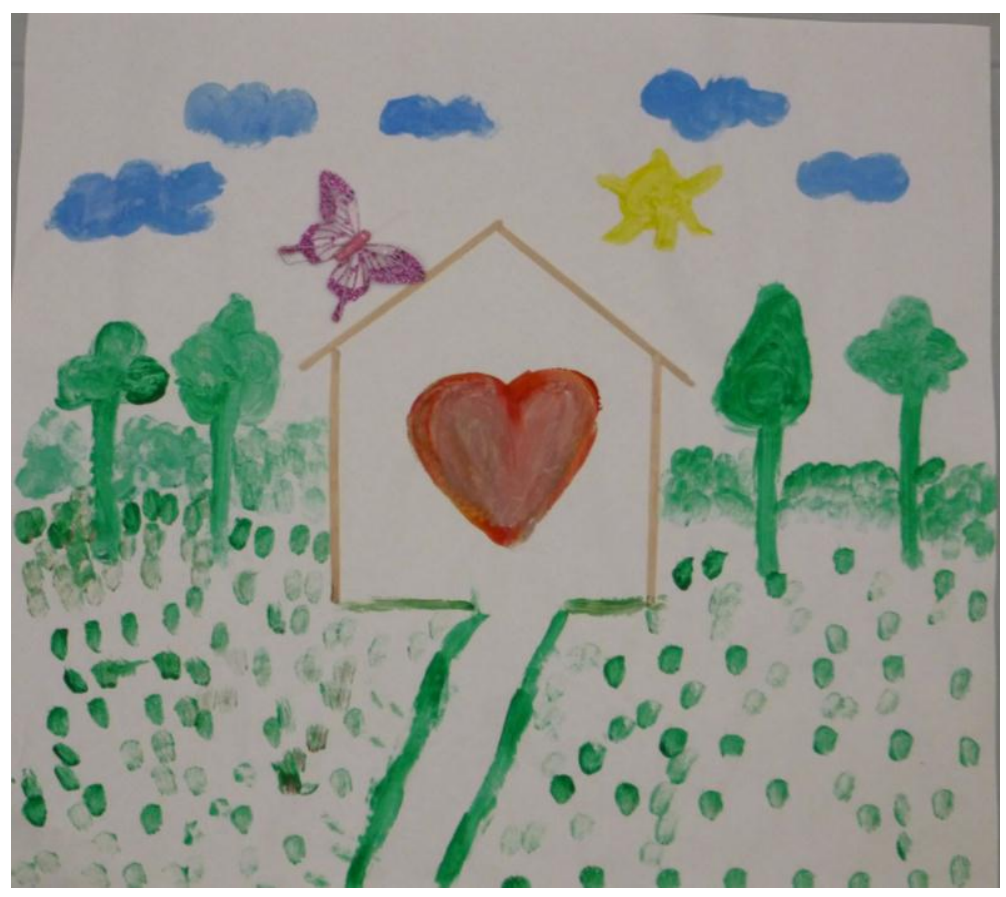

Figure 5 Participant Art Installation

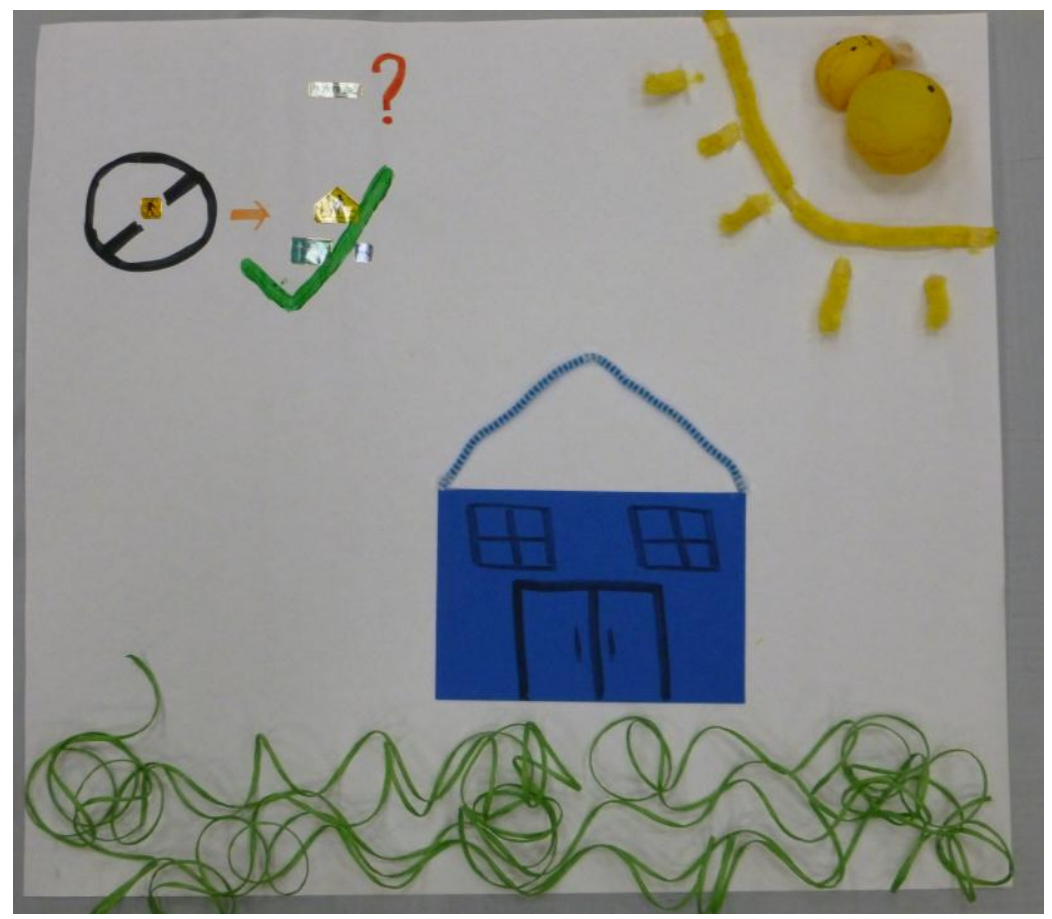

Figure 6 Participant Art Installation 


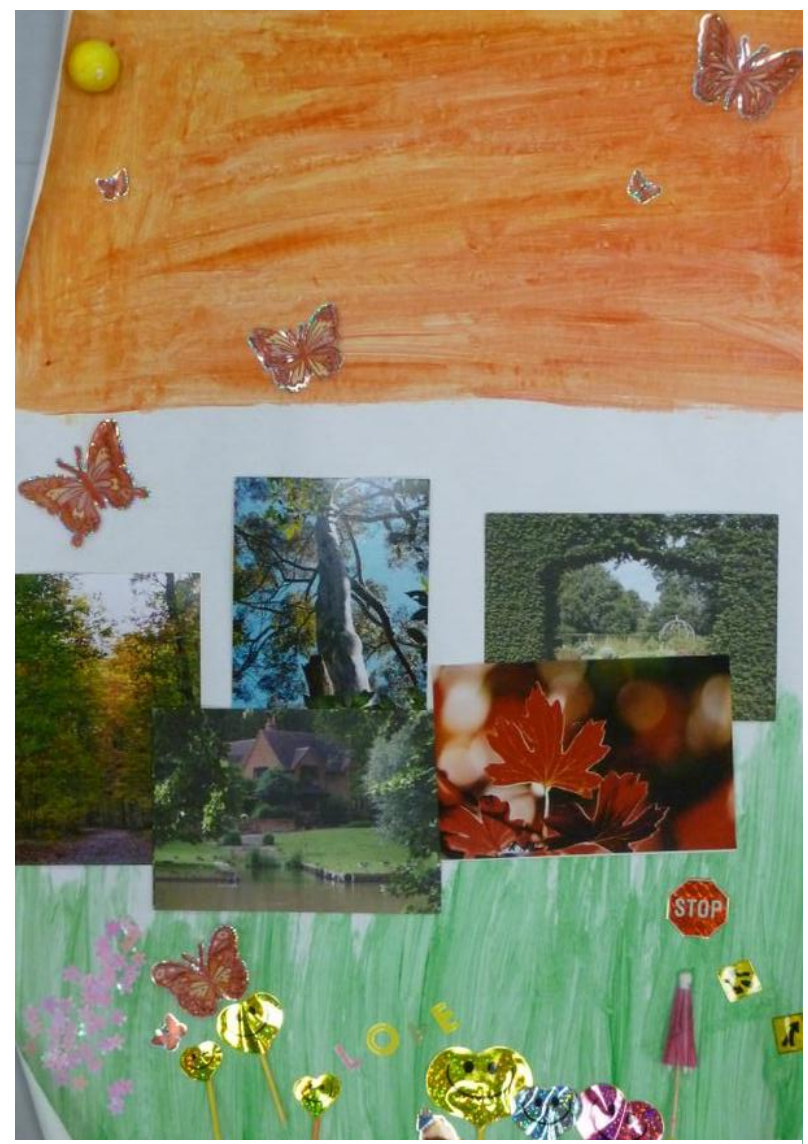

Figure 9: Participant Art Installation

In the second critical reflection workshop, the participants again examined their thoughts and feelings related to aging, by collectively creating a graffiti board (see Figure 10). The board included pictures and words related to aging. The discussion following this activity highlighted the importance of concepts such as health, family and continuity. One participant offered the following insight regarding continuity.

A lot of the stuff that was important to you when you were young, is still important to you when you're older. Like it's very consistent...because if that was important to you when you were younger, it's still going to be just as important to you in the home. You have to take your bag, you have to make sure you look nice to go to breakfast. It doesn't matter. 
That's important to you. And that 's the same regardless of what it is. There's a part of yourself that doesn't change. (Critical Reflection Workshop 2, Participant 3, 905-911)

Importantly, the participants seem to describe the 'healthy' aging process. Furthermore, any of the participants chose to compare the process of aging to the growth of a tree. This is depicted in the following quotes.

I was saying how it goes through seasons. How the leaves fall for one season and then they bloom again. Just like the seasons of life...just circumstances. And again with the individuality, it's different for every tree, every person. (Critical Reflection Workshop 1, Participant 1, 411-413)

We also talked about giving back and how important that is. For an elderly person to feel like they've contributed to society. And so with the tree, when trees die they fall over and become a part of the earth and they become compost and helping other plants grow. It's sort of like leaving a legacy like you were saying for like generations to come. (Critical Reflection Workshop 1, Participant 5, 414-417)

When asked to think about aging within a nursing home or the LTC environment, the participants constructed an insightful metaphor. The following quote was shared after taking a walk outside to reflect on the discussion related to aging.

We went to the quad, and you sort of like see the trees, and the flowers and the mulch and everything and it's sort of this manmade creation of like nature and it's not in it's natural environment. So, it just made me think of you know, just how we put like old people into this box and like this how they are and this is how they should be. We have this picture of them and it's not like truly who they are. And it's also related to how nursing homes are institutionalized and how we make it how we think it should be. And instead of looking at nature in it's wild, natural environment, when it's so much more beautiful and the flowers can just grow as they are. We represent it instead as like, this pot needs to be here and this tree needs to be here and that sort of thing. (Critical Reflection Workshop 1, Participant 5, 369-377)

There is a clear disconnect between the participant perceptions of 'healthy' aging and aging within the LTC environment. 


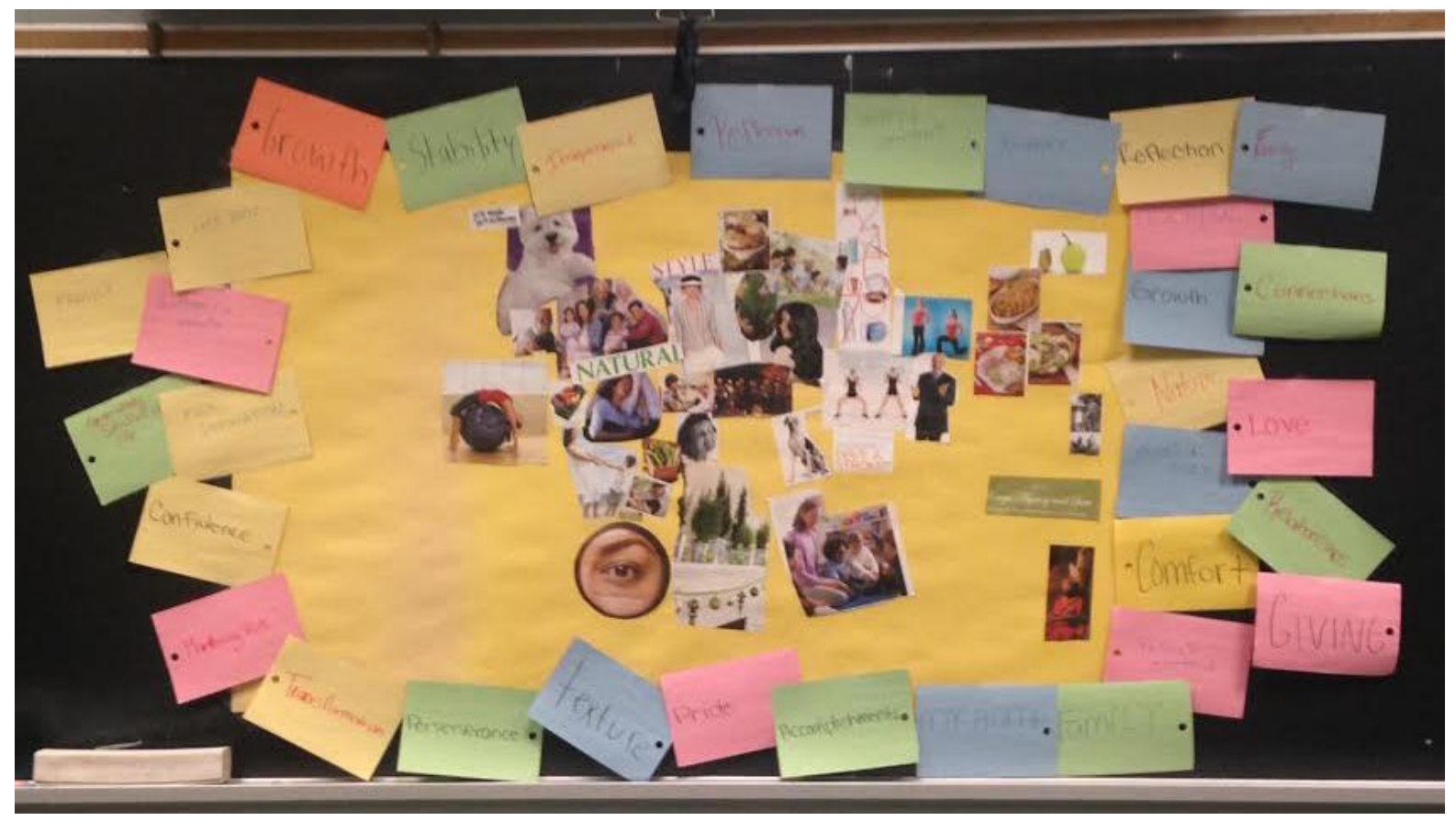

Figure 7 Graffiti Board Depicting Aging

\section{Summary}

The first critical reflection workshop concluded with the participant selection of Evoke cards that inspired their development of personal mantras to guide their gerontological nursing practice as they entered their placement. The second critical reflection workshop culminated in the creation of a collective vision statement articulating the purpose of gerontological nursing (Warfield \& Manley, 1990). The statement is below.

We believe the ultimate purpose of gerontological nursing is providing quality care that it patient-centred and family-centred for the aging population. We believe this purpose can be achieved by a system that is passionate about gerontology, with caring and positive attitudes and beliefs, and being equipped with the right skills, approaches and resources. We believe that factors that help us achieve this purpose are positive collaboration with family members and the healthcare team, appropriate use of personal resources and a positive environmental structure. We believe that the factors that hinder us from achieving this purpose are the cultures and norms of the work environment, organizational structure and personal attitude of the nurse. (Critical Reflection Workshop 2, 1082-1090) 
This statement contains elements related to the categories of relationships, contextual factors and feelings. Furthermore, this statement concisely addresses the initial research questions, as the vision incorporates new insights related to aging, gerontological nursing and the LTC environment

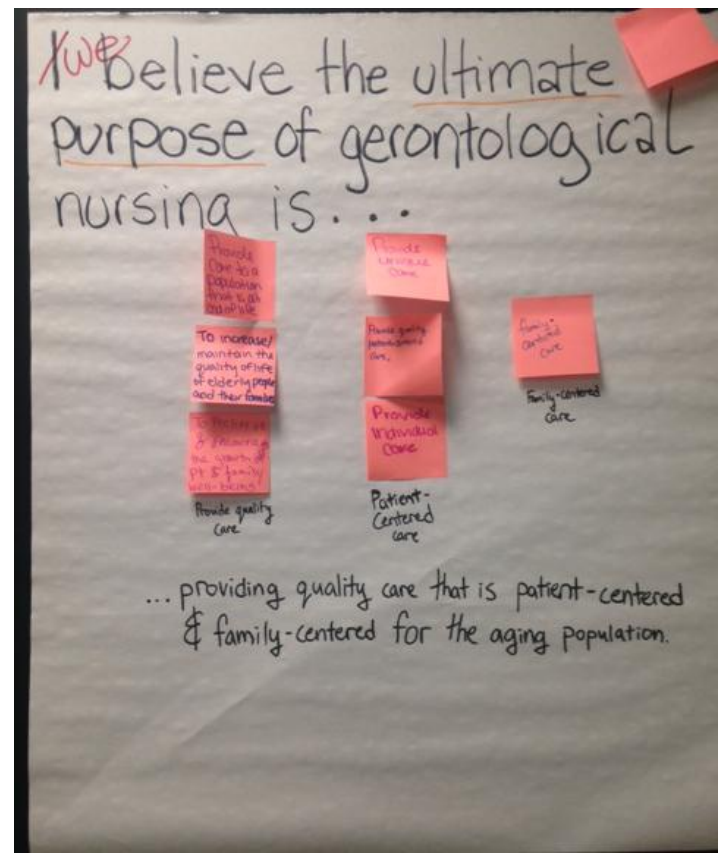

Figure 8 Shared vision statement

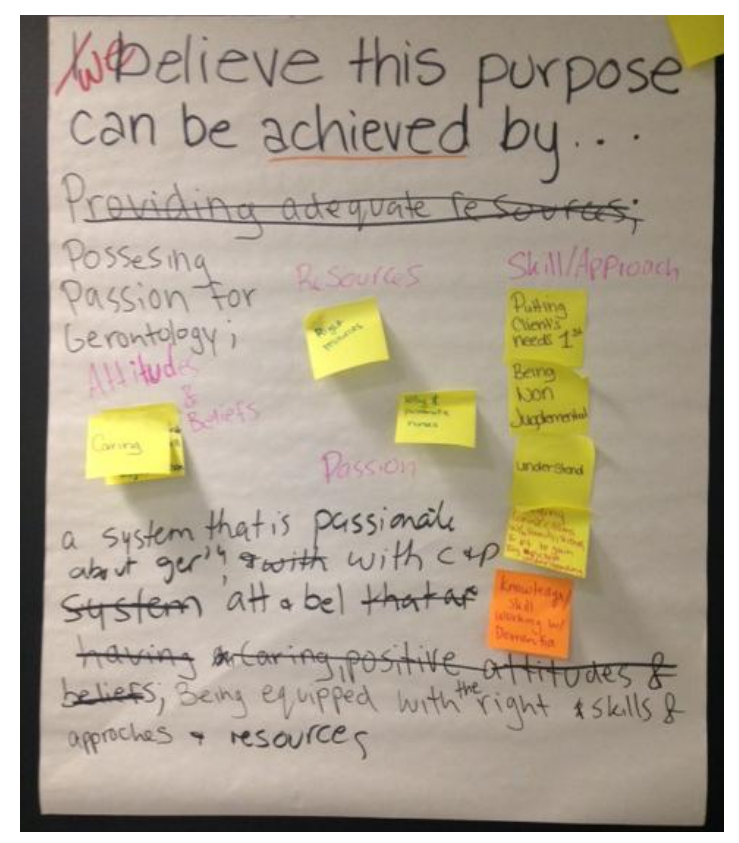

Figure 9 Shared vision statement 


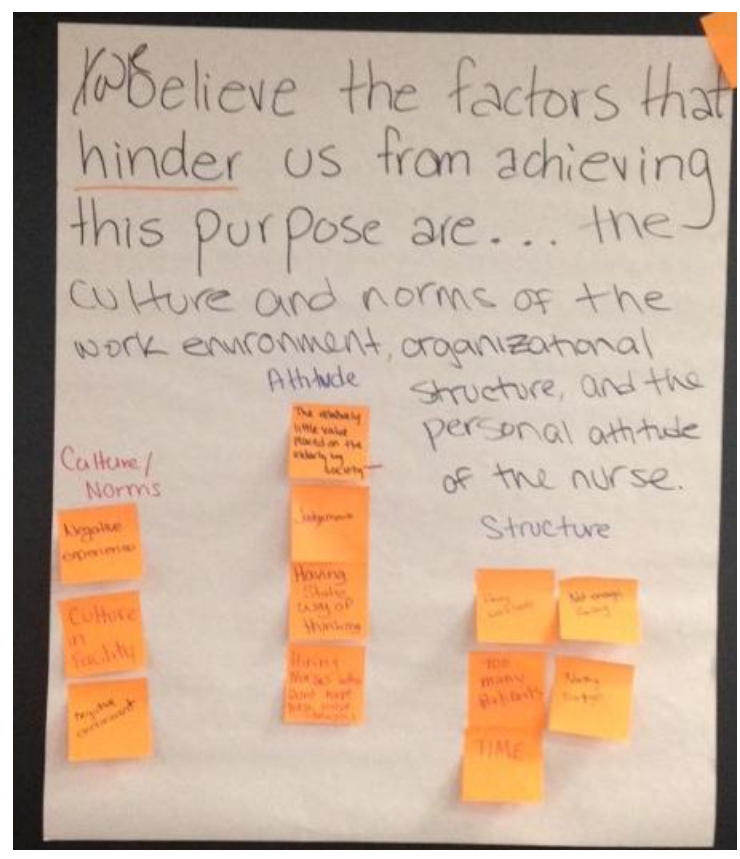

Figure 10 Shared vision statement

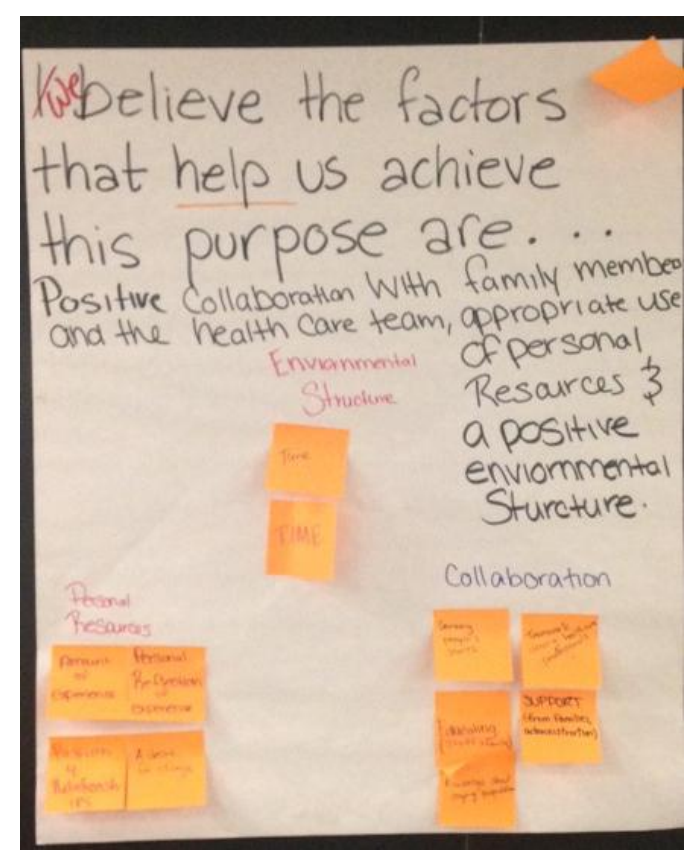

Figure 11 Shared vision statement

\section{Participant Feedback on Critical Reflection Process}

Although the research questions focused mainly on exploring the participant views on

LTC, aging and gerontological nursing, an understanding of how the participants experienced the critical reflection workshops is important, as this is a novel approach. Participants offered feedback during both workshops. Most participants shared that they enjoyed engaging in creative expression. One participant shared that she enjoyed this, despite not thinking of herself as "artsy". Regarding the critical aspects, participants shared the value of the experience in framing their anticipations for their LTC placement. The following participant quotes capture the "new perspective" facilitated by the workshops.

I think as much as this is like a research study, this is very helpful in preparing me for going into my placement and reflecting on like what are my expectations? What do I want to be in this placement? That sort of thing and just taking that and I think that it's just the perfect way to start this placement. And it's given me a new perspective which is just great, so I'm happy about that. (Critical Reflection Workshop 1, 657-660)

It did, as well for me, change my perspective as to how to approach my placement. You know it's so easy to be like, oh I'm in a long-term care facility, like I'm dealing with old 
people, I'm going to be doing like basic nursing care, just medications, but that's not always the most important thing. I feel like personally, forming those hard, they're not hard relationships, but forming relationships with people who have dementia is more difficult than doing any other kind of nursing task. So I think this gave me a new perspective as to how I look at my learning opportunity here. (Critical Reflection Workshop 1, 673-679)

The participant quotes further emphasize growth and the realization of learning opportunities. This is congruent with critical creativity, as this new awareness builds potential to engage in transformation and ultimately, human flourishing.

At the second critical reflection workshop, the participants continued to share feedback regarding how the workshops have helped them. One participant shared, "This process was invaluable. I think everyone should get to do this.” (Critical Reflection Workshop 2, 1219). Another participant expressed feeling as though more workshops would have been helpful and elaborated that, "a lot of the time, this was far more valuable than a lot of time spent at my placement." (Critical Reflection Workshop 2, 1201-1202). 


\section{Chapter VI: Reflection}

Within practice development methodology, structured models for personal reflection offer a way to strengthen reflexive practice and engage in deep critical reflection (RCN, 2007). The following is a descriptive reflection, incorporating data from observational and reflective field notes to enhance the researcher's description of the mood, tone and feel of the workshops.

\section{Description}

The purpose of the first critical reflection workshop was to explore the participant assumptions and anticipations about aging, gerontological nursing and LTC. Each of the six participants was welcomed into the workshop room by researcher and expert facilitator. The participants were invited to choose a seat in a circular arrangement of chairs. Light refreshments were offered to further create a comfortable atmosphere. Participants seemed comfortable, but were relatively quiet prior to the start of the workshop.

During the first activity, in which the participants selected and shared Evoke cards, participants seemed engaged and eager to share. This was reflected in their open body language and enthusiastic tone of voice. I was happily surprised that the participants did not seem to be nervous when speaking in front of the group. This may have been due to the safe atmosphere reinforced by the facilitator and relatively small size of the group. The high level of engagement continued throughout the workshop, as there were very few moments when participants needed to be prompted to participate.

I felt the level of interest increase when participants were asked to create an art installation to represent their aging journey. In my field notes, the atmosphere in the room is described as "quiet, but intense" and participants approached the activity with "an almost childlike earnestness" (Field Notes). It seemed as though the participants were grateful for the 
opportunity to use multiple senses to engage with their creative selves. Similarly, the participants responded well to the opportunity to engage in a nature walk, while collectively reflecting on the shared statement regarding aging. Although the participants were not accompanied by the facilitator during the walk, the benefit of the time to connect with nature was apparent in their rich, nature-inspired metaphors.

The last activity, in which the participants selected Evoke cards to guide their intention for their nursing practice in placement was particularly moving moment for me. As I observed the participants describe their intentions for practice, I saw and heard excitement, hope and a desire to bring positivity in the actions and voices. Many of their intentions emphasized building therapeutic relationships with residents, which may have stemmed from an enhanced understanding of aging.

During this workshop, I sensed a shift in the participant understandings and feelings regarding their LTC placement. The participants were engaged in the activities and offered honest perspectives of their anxieties prior to entering the LTC setting. I sensed the participant anxiety transform into excitement, as they deconstructed their realizations and assumptions through the critical reflection activities. Furthermore, the participants responded well to the insights and anecdotes shared by the facilitator, an expert gerontological nurse. The participants showed a great appreciation for the facilitator's passion for gerontology.

The aim for the second critical reflection workshop was for participants to explore their realizations of aging, LTC and gerontological nursing. Four of the initial six participants returned. After the participants shared their narrative experiences of their LTC placement, the atmosphere of the room felt heavy. In my reflective notes, I expressed feelings of guilt. I remembered their optimistic intentions for placement, and noticed how their real world 
experiences had worn them down. It was a look that I recognized, from my own practice during my first year of nursing. Despite the tone, it seemed as though sharing the narratives was a cathartic experience. It was during this activity that I noticed the participants come together as a community of learners. Each was engaged in listening to the stories of the others. They seemed to experience each story as a group, as they all laughed, cringed and frowned together. It was a moment of extraordinary support facilitated by participants' honesty and depth of insight.

This collective group bond paved the way for rich discussion during the creation of the graffiti board to represent aging and the design of the shared vision statement for gerontological nursing. The body language of the participants remained open and they seemed to be more active during these activities. Towards the end of the workshop, the participants seemed to greatly enjoy participating in the stop/start/continue activity. Despite the heavy tone initiated by the narratives, participants shared hopeful insights about aspects of LTC that they could work to improve as future Registered Nurses. I noted their strength and resiliency in my reflective notes. Even after the facilitator had pointed out that the workshop was nearing the end time, the participants continued the discussion for an extra 30 minutes. I felt personal satisfaction knowing that this experience was one that the participants felt was important enough to allot extra time.

\section{Analysis and Evaluation}

From the reflective description, skilled facilitation and active learning methods offered a way for the participants to critically reflect in a way that may not have been previously exposed. The participants wholeheartedly engaged the activities, contributed to rich discussion and presented their ways of knowing in novel ways, such as through art and metaphor. The small group format created an intimate setting, in which participants formed a community of learners. Within this community, the participants supported and at times, challenged one another. 
Drawing on my field notes and reflective notes, I felt that two, four-hour workshops were not adequate to fully explore the participant assumptions, anticipations and realizations of aging, LTC and gerontological nursing. I felt that the luxury of more time would have facilitated a deeper, more critical dive into the research questions. However, the workshops exceeded my expectations, in that both engendered feelings of hope and opportunity. For instance, participants entered the first workshop with feelings of anxiety, and left with a thoughtful intentions for the nursing practice. At the second workshop, participants entered with heavy stories of the LTC placement, and were able to leave feeling as though they had to potential to improve the LTC practice setting. The workshops brought together PD methodologies, critical creativity and active learning theory to create a unique environment in which participants were able to build their own community of learning to support their transformation. The workshops provided an open space for participants to reframe their assumptions and open up to possibilities. The following two complementary haiku poems reflect my experience of critical creativity during the critical reflection workshops.

Creativity

Illuminates hidden truths

Expanding knowing

Critical insights

Solitary and combined

Build hope and wisdom

Following data collection and analysis, I reflected on the possibility of allowing students more frequent access to such critical reflection workshops. As previously mentioned, I was a bit uncomfortable planning one workshop before participant placement and the final workshop after 
placement. I knew, from personal and professional experience, that the optimism generated in the first workshop would be repeatedly challenged during their placement. I wondered how the participants would cope with this and if they would return to the second workshop. My desire to hold more frequent workshops was not feasible due to student schedules. Furthermore, I also thought about how collecting demographic data may have further informed the study and personalized the critical reflective activities. Knowing more about the participants may have strengthened the transferability of findings, as well as enhanced the participant experience.

This reflection prompted a few questions: How are nursing students socialized into thinking about gerontological nursing? How do faculty support students during their placement experience? How do faculty address issues arising from cognitive dissonance during the student placement?

The questions inspired by my experience are complex and require future research to expand and extend our knowledge of the student experience of LTC placement. However, the insights that I have gleaned from this study will inform my practice, as a clinician, future educator and researcher. In my role as a clinician mentoring new staff and students, I have a new awareness of the intensity of their experience in adapting to the contextual challenges of setting in addition to therapeutically managing the care needs of complex individuals. As a future educator and researcher, I acknowledge the value in engaging in creative learning-teaching methods and research dissemination strategies. Ultimately, releasing the creative imagination of students, clinicians or educators, will support content to be received in a way that facilitates building connections to existing knowledge. 


\section{Chapter VII: Discussion}

This qualitative descriptive study has sought to describe the assumptions, anticipations and realizations of fourth year undergraduate nursing students in relation to aging, gerontological nursing and LTC, as they actively engaged in critical reflection during their LTC placement. The findings of this study offer support for various bodies of literature informing the nursing student experience in the LTC setting. In this section, the relevant findings will be situated within the existing literature to illuminate the ways in which this study contributes to what is known about nursing student anticipations, assumptions and realizations of LTC.

\section{Key Findings}

The findings of this study may be summarized in the final statement constructed by the participants, which describes the purpose of gerontological nursing, as it encompasses the learning from deconstructing their anticipations, assumptions and realizations of LTC. The statement emphasizes the importance of person-centredness in the care of the older adult in the LTC setting. The incorporation of 'caring and positive attitudes and beliefs' reflects the sentiments from the participant mantras upon entering the LTC placement. The acknowledgement of contextual factors impacting practice, such as workplace cultures and organizational structure reflect the participant realizations following their experience in the LTC setting.

\section{Relationships}

The participants in this study expressed anticipations related to building therapeutic relationships with residents prior to entering the LTC placement. The creation of mantras to guide their gerontological nursing practice emphasized intentions to embody concepts such as independence, empowerment, partnership and tenderness in their actions. Following their 
experience of LTC placement, participants reported valuing the time spent with residents. This supports existing literature, which describes nursing students as enjoying the process of building relationships with residents and refining their understanding of person-centred care (Banning et al., 2006; McGarry et al., 2009).

Student assumptions informing their perceptions of residents in the LTC setting were uncovered through the use of critical reflection activities incorporating Evoke cards or artifacts. Participants described residents in nursing homes as being treated as a pets or 'left to rot'. The revelation of such assumptions may have allowed participants to gain an understanding of the resident experience of LTC. This insight may have led to a more empathetic attitude when creating the mantras to guide practice.

Alternately, participants described challenges in building therapeutic relationships with residents due to communication difficulties related to Alzheimer's disease, dementia or other cognitive issues. This supports the work of Robinson and Cubit (2005), as their findings emphasized the difficulty of preceptors in providing emotional support during the process of building a relationship with a resident with a cognitive disorder.

Interestingly, the participants within this study did not reference the physical care provided to the residents in a negative light, as described in a few studies (Abbey, 2006; Lea et al., 2014). Instead, the participants emphasized the activities that they would have liked more time to perform, such as medication administration and wound care. Participants further emphasized that they would have preferred to spend more time with residents to enhance the therapeutic relationship and better understand the resident holistically, especially within the context of his or her family. 
Prior to their LTC placement, the participants did not describe their anticipations or assumptions regarding their relationship with their preceptor, as they focused mainly on their anticipations related to building therapeutic relationships with residents. The participant discussions of their initial interactions with their preceptors revealed underlying assumptions related to the preceptor attitudes toward the LTC environment. Preceptor statements such as, 'it's going to be tough for you', indicated to the participants that the LTC environment was not desirable environment in which to work.

The detailed descriptions given by the participants of their relationship with their preceptor support findings from the greater body of literature that highlight the importance of the quality of this relationship (Carlson \& Idvall, 2012; Banning et al., 2006; Berntsen \& Bjork, 2010; Brynildsen et al., 2014; Lea et al., 2014; McGarry et al., 2009; Robinson \& Cubit, 2007; Skaalvik et al., 2011; Skaalvik et al., 2012; Wade \& Skinner, 2001). Participants within this study reported feeling unsupported by their preceptor, especially when asked to complete tasks beyond the participants' perceived level of competence. Two studies emphasized the incongruence between the preceptor and student expectations (Brynildsen et al., 2014; Skaalvik et al., 2012).

It was further noted by participants that the preceptor was hesitant to provide explanations regarding nursing activities and were dismissive of participant questions at times. Skaalvik and colleagues (2012) emphasize that professional dialogue between the preceptor and student help the student to feel engaged in the learning process. According to Price (2008), cognitive dissonance is a process frequently encountered by new nurses, in which their nursing ideals are challenged by the reality of the practice setting. 


\section{Contextual Factors}

Participants did not discuss anticipations related to contextual factors prior to entering the LTC environment in great detail. One participant metaphorically compared the LTC setting to a pinecone, as they are both 'unappealing'. Another participant drew on a previous community placement experience, in which she perceived the LTC setting to be understaffed. Most of the participants did not anticipate challenges related to contextual factors.

In the second workshop, participants quickly identified contextual factors affecting practice such as insufficient time to complete tasks, high nurse to resident ratios and lack of resources. This supports discussion in the literature pertaining to similar barriers regarding care of residents (Abbey et al., 2006; de Guzman, 2009; McGarry et al., 2009). Within this study, the contextual factors were further described as negatively impacting their relationships with the preceptor and the residents, as little time was left for nurturing relationships.

Participants further identified the hierarchical structure of the LTC setting as a hindrance to communication and teamwork. Although the social structure was not specifically referenced by the participants, the existing literature describes nursing homes to be rated as slightly positive learning environment by nursing students (Berntsen \& Bjork, 2010; Brynildsen et al., 2014; Carlson \& Idvall, 2012; Skaalvik et al., 2011). However, the tools used to rate the LTC environment included diverse criteria related to the unit atmosphere, leadership style of the unit manager, and preceptor relationship (Berntsen \& Bjork, 2010; Brynildsen et al., 2014; Carlson \& Idvall, 2012; Skaalvik et al., 2011). 


\section{Feelings}

A range of feelings were described by participants when discussing their anticipations for their LTC placement, such as anxiety coupled with excitement. The participant anticipations related to their nursing practice focused mainly on building therapeutic relationships with residents, and imbuing their practice with concepts such as tenderness, partnership and support. This is congruent with student descriptions in the literature, where the LTC is viewed as an opportunity to improve patient-centred practice (Lea, 2014; Wade \& Skinner, 2001) or a missed opportunity to learn acute care skills (Abbey et al., 2006; Banning et al., 2006; Wade \& Skinner, 2001).

After experiencing the LTC setting, participants reported a variety of feelings throughout their placement, as indicated by the participants that related to multiple figures on the Blob diagram (Appendix E). Participants were frustrated at times with the lack of communication with their preceptor, but also expressed feelings of pride when completing new skills independently. This further echoes findings in the literature regarding diverse nursing student impressions of the LTC following placement (Banning et al., 2006; Lea et al., 2014; Wade \& Skinner, 2001).

The range of student feelings may be similar to those of students experiencing placement in settings other than LTC. However, the feelings described by the participants within this study highlight the dissimilarity of LTC with other, often more acute, healthcare settings. For example, LTC has been described in this study and many others as having a particularly disproportionate nurse to resident ratio (OANHSS, 2012; Silversides, 2011). Managing the needs of multiple floors of residents, as described by the participants (Critical Reflection Workshop, Participant 6, 401-407), may be overwhelming to a student, still developing their critical thinking, judgment and expertise. LTC is further unique in that it is a primarily nurse-led environment. Although this 
offers gerontological nurses autonomy, it may be intimidating to students entering with a focus on building relationships with residents and learning basic nursing care. Educators and preceptors may need to reframe nursing student expectations when entering LTC and discuss the complexities and challenges unique to this environment.

\section{Aging}

Participants entered the LTC setting with healthy views of aging, characterized by words such as connections, growth, reflecting on the journey, peace and achievements and metaphors of vibrant trees. Interestingly, when asked to think about aging with LTC, the participants described the metaphor depicting 'forced naturalness', in which a tree is forced to grow in an artificial environment that inhibits its potential.

The findings from this study reflect findings within the literature related to the attitudes of nursing students regarding older adults. Although many quantitative studies report nursing students to have moderately positive attitudes toward older adults (Ayoglu et al., 2014; Henderson et al., 2008; McKinlay \& Cowan, 2003; Ryan \& McCauley, 2004; Zverev, 2013), a few qualitative studies found students to associate aging with key words such as dependence and disability (Celik et al., 2010; Henderson et al., 2008; Moyle; 2003).

Following their experience in LTC, the participant views of aging within the LTC setting had expanded, as participants emphasized the importance of health, family and continuity to residents. This may be considered within the context of studies citing an improvement in student attitudes toward older adults after an LTC placement, as students begin to understand the complexity of aging within this setting (Bleijenberg et al., 2012; Happell, 2002, Hartley et al., 1995; Scheffler, 1998). 
Findings of this study support much of what is known about the student experience in LTC, as well as nursing student attitudes toward older adults. However, the use of critical reflection workshops, underpinned by critical creativity (McCormack \& Titchen, 2006), has allowed for an enhanced awareness in the way in which nursing students experience the LTC setting. Each category of the findings, and subsequent discussion, describes the evolution of the participant realizations as increasingly complex, as the engagement in critical reflection deepened. Perceptions of the residents in the LTC setting expanded into an awareness of the complexity of each resident within the context of aging and his or her life narrative. Initial practice mantras, focused on building therapeutic relationships were challenged by the contextual factors. Thus the use of critical reflections helped participants in realizing gerontological nursing as 'complicated'.

\section{What this Study Adds}

The critical reflection workshops, underpinned by critical creativity, offer a novel way to engage students in their learning during their LTC placement. The various critical reflection activities engaged the participants in using multiple senses and created opportunities for doubleloop learning through dialogue with self and others. Encouraging students to reflect through creative expression and critical dialogue created opportunities for conversations of a different nature. For instance, the use of Evoke cards and artifacts gave participants the opportunity to craft beautiful metaphors to describe their perceptions of LTC and gerontological nursing practice. Furthermore, many particularly insightful metaphors emerged from the time participants spent reflecting during the nature walk.

The use of multiple critical reflection activities, such as the visualization activity, creation of art installations and development of a collective aging definition, to understand the participant 
understanding of aging was particularly insightful, as these activities revealed participants' healthy views of aging. Suggesting perhaps it is not aging itself, but when aging occurred in an institutionalized setting that presented challenges. This idea was explored in the collective 'forced naturalness' metaphor, which compared the older adult to a tree made to grow in an artificial setting.

Providing a safe space for participants to share their narratives of their placement experience revealed the crucial role of the preceptor in facilitating learning within the LTC setting and reframing challenges related to gerontological nursing. Group dialogue led to realization of how various contextual factors, such as organizational structure and insufficient resources impact nursing practice. This contributed to participant feelings of cognitive dissonance and difficulties linking theory and practice. The identification of these challenges highlights the intention of critical reflection, as participants were able to deconstruct their experience in a way that revealed underlying meanings and assumptions.

Looking further into the concerns the participants expressed regarding the difficulties linking the realities of practice to theory, it is possible to begin to critique the use of skilled facilitation within this study. The role of the facilitator was to guide the participants in the critical reflection process (Larsen et al., 2005). Titchen (2003) further interprets the facilitator to function as a critical companion, or an individual who "accompanies another on an experiential learning journey, using methods of 'high challenge' and 'high support' in a trusting relationship" (p. 33). However, critical companionship requires relatively frequent communication between both individuals, in order to provide adequate support and guidance (Titchen, 2003; Wright \& Titchen, 2003). The learning experiences of the participants may have been enhanced by more frequent opportunities to engage in reflection with a critical companion. 
This study has furthered understanding related to the use of critical creativity in an academic setting. The critical reflection activities used creative expression and critical dialogue to engage the participants in the use of multiple senses to access their embodied knowing. This novel method of learning provided participants the opportunity to explore the anticipations, assumptions and realization of LTC, in regards to the aging, gerontological nursing and LTC setting. 


\section{Chapter IX: Implications and Future Research}

This study primarily has implications for nursing education, but may also inform practice and policy. Regarding education, there may be interest in using critical reflection activities as a strategy to help nursing students deconstruct the factors informing their experiences, thoughts and feelings. The described critical reflection activities, underpinned by critical creativity, are versatile and may be adapted for use in various settings, specialties and by diverse groups. The findings of this study could assist educators in enhancing a nursing curriculum that supports the student placed in the LTC setting. Furthermore, the challenges highlighted by participants regarding their relationship with their preceptor and linking nursing theory to practice, may be areas of interest to educators seeking to support the student before, during and after placement.

In regards to nursing practice and policy, the findings reveal a number of contextual factors that influence nursing practice such as high nurse to resident ratios, insufficient resources and hierarchical organizational structures. Although known in the literature, this study may provide qualitative insights to further support policy promoting changes to practice that emphasize person-centred care.

The findings of this study on the nursing student experience in LTC placement, can inform future research on their career intentions in relation to seeking roles in LTC settings. Future research may also explore the use of critical reflection. For example, a longitudinal study exploring the integration of critical creativity into the curriculum for first to fourth year nursing students may extend our understanding of the benefits of this educational innovation. The methodology informed by critical creativity (McCormack \& Tichen, 2006) may be applied to diverse contexts, extending beyond LTC. 


\section{Chapter X: Conclusion}

This qualitative descriptive study described the assumptions, anticipations and realizations of fourth year undergraduate nursing students regarding aging, gerontological nursing and LTC, as they engaged in critical reflection during their LTC placement. The findings support the existing literature related to the nursing student experience in the LTC setting. However, findings from this study reveal the critical role of the preceptor in the student's learning experience, the positive views of aging held by the students, and the realization of contextual factors affecting gerontological nursing practice. This study offers a novel way in which to explore nursing student assumptions, anticipations and realizations through the use of critical reflection, underpinned by critical creativity theory (McCormack \& Titchen, 2006). 
Appendix A

Recruitment Flyer

RYERSON

UNIVERSITY

\title{
Are you a nursing student entering a long-term care clinical placement during the Fall 2015 term?
}

\author{
Student Participants Needed for a Research Study Entitled:
}

\section{Using Critical Reflection to Understand the Perceptions and Experiences of Fourth Year Undergraduate Nursing Students Placed in a Long-Term Care}

Purpose of this Study:

- To understand fourth year nursing student perceptions and experiences related to clinical placement in the long-term care setting.

You Are Eligible For This Research Study If:

- You are a fourth year undergraduate nursing student.

- You are will be completing your Fall 2015 clinical placment in a long-term care setting.

Study Involvement:

- By joining this study, you will need to participate in two focus group discussions.

- Each focus group will contain a 90-minute discussion, a 30-minute nature walk and a 60minute discussion.

Study Benefits:

- You may not experience any direct benefit from the activities associated with this study.

- Your participation will shed light on the nursing student experience of long-term care.

- Your participation will give you the opportunity to engage in critical reflection.

- You will receive a \$5 Tim Card, as compensation for your time.

Study Risks:

- Participation in a focus group discussion has the potential to elicit strong emotions

For more information about this research study, please contact the researcher/graduate nursing student, Alyssa Indar, by email at aindar@ryerson.ca.

This study is being conducted in partial requirement for the completion of a master's thesis under the direct supervision of Dr. Sherry Espin (sespin@ ryerson.ca). 
Appendix B

Letter to Inform Faculty of Study Purpose

\section{RYERSON} UNIVERSITY

Dear Ryerson Nursing Faculty Member,

My name is Alyssa Indar and I am a current student in the Masters of Nursing (Thesis Stream) Program. The purpose of this e-mail is to seek your permission to post an electronic flyer on your D2L course shell, as I am recruiting fourth year undergraduate nursing students for my research study. I am not asking that you promote this study in any way; I am asking that you consider posting the flyer on the course shell for students to view at their leisure. Please find attached a copy of the flyer. Please note that Dr. Nancy Purdy (AD - Collaborative Program, and Member, Collaborative Program Management Committee), Dr. Don Rose (DCSN - Director), and Dr. Sharon Paton (4th Year Lead) have been made aware of this study.

This study is being conducted by as a requirement of the Master of Nursing (Thesis Stream) Program, under the direct supervision of Dr. Sherry Espin, an Associate Professor at Ryerson University. The other Thesis Committee Members are Dr. Karen LeGrow and Dr. Nadine Janes. This qualitative descriptive study will describe the experiences of fourth year undergraduate nursing students completing a clinical placement in a long-term care setting, as they actively engage in a critical reflection activity guided by an expert facilitator, Dr. Nadine Janes, to explore their perceptions and experiences of their placement within the long-term care setting. Nursing students who have been assigned to a long-term care home placement during the Fall 2015 term are invited to participate in this study.

Participation requires that the individual attend two, three-hour focus groups; one before placement and one after placement. Participants will be informed that their participation in this study will have no bearing on their academic standing in the collaborative program or within their NUR417 course and relationships with Ryerson faculty including the researchers involved in this study. Participation is voluntary. If you would like more information about the nature of this study before making your decision, please e-mail me at aindar@ ryerson.ca, and we will negotiate a convenient meeting time to engage in a more fulsome discussion.

Thank you, Alyssa Indar RN, BScN 
Appendix C

Participant Informed Consent Form

\section{RYERSON}

UNIVERSITY

\section{Ryerson University \\ Consent Agreement}

You are invited to participate in a research study. Before you consent to participate, please read this consent form and ask any questions so that you understand what your participation will involve.

Using Critical Reflection to Understand the Perceptions and Experiences of Fourth Year Undergraduate Nursing Students Placed in Long-Term Care

\section{INVESTIGATORS:}

This study investigator is Alyssa Indar, a Registered Nurse, and current student at the Yeates School of Graduate Studies at Ryerson University. This study is being conducted by the investigator as a requirement of the Master of Nursing (Thesis Stream) Program, under the direct supervision of Dr. Sherry Espin, an Associate Professor at Ryerson University.

\section{PURPOSE OF THE STUDY:}

The purpose of this study is to describe the perceptions and experiences of fourth year nursing students placed in long term care clinical settings. We would like to speak with fourth year nursing students completing a clinical placement in a long-term care setting. This research study will not influence the student's academic standing in the Collaborative program or within the NUR417 course and relationships with Ryerson faculty including the researchers involved in this study, as the researcher will maintain your privacy and confidentiality. Participation is voluntary.

\section{WHAT PARTICIPATION MEANS:}

Participation in this study includes the following:

- You will participate in 2 focus groups; the first before your clinical placement, and the second after your clinical placement. Each focus group will be approximately 3 hours in length and include 6-8 participants. Each focus group will also include a 30-minute nature walk.

- You will be audio-recorded during the focus groups.

- You ongoing participation is voluntary. You may withdraw from the study at any time. 


\section{POTENTIAL BENEFITS:}

You will not benefit directly from this study. The findings of the study may contribute to a greater understanding of the nursing student experience in long-term care placement.

\section{WHAT ARE THE POTENTIAL RISKS TO YOU AS A PARTICIPANT:}

During the focus group, some questions may elicit strong emotions. If this occurs, you may choose not to answer the question or you may choose leave the focus group. If you feel that you need further support, please see the information regarding counselling on last page of this document. Participation is voluntary and you may withdraw from the study at any point.

The researcher will ask all participants to keep all discussion information confidential at the beginning of each focus group, however confidentiality cannot be guaranteed.

\section{CONFIDENTIALITY AND PRIVACY:}

Confidentiality will be respected and no information that can be identified as belonging to you will be shared without you consent, unless required by law. For instance, any discussions regarding abuse of a resident would require the researcher to contact the NUR417 Course Lead.

The study investigator, Alyssa Indar, is the only individual with access to data containing participant identifiers. The committee members, Dr. Sherry Espin, Dr. Karen LeGrow and Dr. Nadine Janes will only have access to data that has been de-identified by the study investigator. It is emphasized that Dr. Sherry Espin and Dr. Karen LeGrow will not have access to data containing participant information.

Your consent document and data containing your personal information will be kept in a locked drawer in the researcher's locked home office for the duration of the study and will be destroyed at the study conclusion. The de-identified study data will be kept on an encrypted, password protected USB key. The data will be kept for a maximum of 5 years, in the event that the principle investigator wishes to conduct a secondary analysis of the original data. The data will be destroyed five years after the completion of the thesis study regardless of whether secondary analysis has been completed. It is not the intention of the other members of the thesis committee, Dr. Sherry Espin, Dr. Karen LeGrow and Dr. Nadine Janes to use this data for any secondary analysis as part of another or larger study.

The publication(s) or presentation(s) related to this research study will not contain any personal identifiers.

\section{INCENTIVES FOR PARTICIPATION:}

Participants will receive an honorarium of a gift card to Tim Horton's worth $\$ 5.00$. 


\section{COSTS TO PARTICIPATION:}

There will be no additional costs, as the focus groups will take place on the Ryerson University campus.

\section{VOLUNTARY PARTICIPATION AND WITHDRAWAL:}

Participation in this study is completely voluntary. If you feel uncomfortable at any point during the study, you may choose to not participate any component or you may choose to withdraw altogether. If you decide to withdraw from the study, it is not guaranteed that your contribution to the focus group will be removed, as it may not be distinguishable on the audio recording.

If you choose withdraw from the study, this will have no influence on your academic standing, relations with Ryerson University or the research study investigators.

\section{QUESTIONS ABOUT THE STUDY:}

If you have any questions about the research now, please ask. If you have questions at any time about the research, please contact:

Alyssa Indar, RN, BScN

aindar@ ryerson.ca

Sherry Espin, RN, BScN, Med, PhD

sespin@ryerson.ca

416-979-5000 ext. 7993

Ryerson University

350 Victoria Street

Toronto, ON

M5B 2K3

This study has been reviewed by the Ryerson University Research Ethics Board. If you have questions regarding your rights as a participant in this study please contact:

Research Ethics Board

c/o Office of the Vice President, Research and Innovation

Ryerson University

350 Victoria Street

Toronto, ON M5B 2K3

416-979-5042

rebchair@ryerson.ca 


\section{Exploring Critical Reflection of Fourth Year Undergraduate Nursing Students Placed in a \\ Long-Term Care Setting}

\section{CONFIRMATION OF AGREEMENT:}

The research study has been explained to me and my questions have been answered to my satisfaction. I agree to participate in this study and may withdraw my consent at any time. I have been told that my personal information will be kept private and confidential; no information will be disclosed without my permission unless required by law. I have been told I will be given a signed copy of this consent form.

Name of Participant (please print)

Signature of Participant

Date

I agree to be audio-recorded for the purposes of this study. I understand how these recordings will be stored and destroyed. I understand that I can request that audio recording be stopped at any time during the focus group.

Signature of Participant

Date

I understand that pictures of artwork created by myself or as part of a group, as well as pictures of selected artifacts/objects will be used for the purposes of this study. I acknowledge that the described pictures will not contain any personal identifiers.

Signature of Participant

Date 


\section{RYERSON UNIVERSITY: COUNSELLING SERVICES}

If you experience an emotional response as a result of participating in the focus group discussion, please do not hesitate to contact the Ryerson University Centre for Student Development and Counselling. All services offered are free and confidential. Their contact information is as follows:

Location: Jorgenson Hall (JOR-07C)

Telephone: (416) 979-5195

E-mail: csdc@ryerson.ca

Website: www.ryerson.ca/counselling 
Appendix D

Critical Reflection Workshop Guides

\section{Workshop 1: Setting A Course for Learning}

This workshop provides participants with the opportunities to:

1. unearth their assumptions and anticipations about their long-term care placement;

2. link their values and beliefs about aging and long-term care to their assumptions and anticipations; and

3. set a personal path for learning in and from their long-term care placement that leads to positive growth and development on personal and professional levels.

\begin{tabular}{|c|c|c|c|}
\hline \# & TIME & ACTIVITY & $\begin{array}{l}\text { REQUIRED } \\
\text { RESOURCES }\end{array}$ \\
\hline 1 & $\begin{array}{l}0850- \\
0900\end{array}$ & Introduction to study and signing of consents & Consent forms; pens \\
\hline 2 & $\begin{array}{l}0900- \\
0920\end{array}$ & $\begin{array}{l}\text { Check-in } \\
\text { Spread Evoke cards and artifacts on a table and } \\
\text { invite participants to select } 1 \text { item that reflects } \\
\text { them as a person and } 1 \text { item that reflects their } \\
\text { understanding/ thoughts about LTC. Invite } \\
\text { participants to share their selections with the } \\
\text { large group. }\end{array}$ & $\begin{array}{l}\text { Evoke cards; box of } \\
\text { artifacts }\end{array}$ \\
\hline 3 & $\begin{array}{l}0920- \\
0935\end{array}$ & $\begin{array}{l}\text { Hopes and Fears for Placement } \\
\text { Provide participants with } 2 \text { different colors of } \\
\text { post-its. Invite them to use one color for "Hopes" } \\
\text { and the other for "Fears" related to their LTC } \\
\text { placement. Have participants hang their post-its } \\
\text { on Flipchart sheets. }\end{array}$ & $\begin{array}{l}2 \text { pieces of flipchart } \\
\text { paper posted on the } \\
\text { wall; } 1 \text { titled "Hopes" } \\
\text { and } 1 \text { titled "Fears" }\end{array}$ \\
\hline 4 & $\begin{array}{l}0935- \\
1005\end{array}$ & $\begin{array}{l}\text { Guided Reflection: Understanding Your Own } \\
\text { Aging } \\
\text { [see separate handout] } \\
\text { Create a collage/representation of aging as you } \\
\text { experienced it. Create the collage in silence. }\end{array}$ & $\begin{array}{l}\text { Arts and crafts supplies; } \\
\text { large pieces of paper } \\
\text { (e.g., flipchart) }\end{array}$ \\
\hline 5 & $\begin{array}{l}1005- \\
1035\end{array}$ & $\begin{array}{l}\text { Creating the Building Blocks } \\
\text { Share elements of your reflection and collage with } \\
\text { a partner. Partners will write a narrative of the } \\
\text { other's aging experience. As a duo, draw out } \\
\text { metaphors from the collages and/or narratives } \\
\text { and write them on a piece of the paper. Post the } \\
\text { theme pieces of paper on the wall }\end{array}$ & $\begin{array}{l}\text { Pens and paper; } \\
\text { markers; light coloured } \\
\text { paper cut in halves } \\
\text { (bricks); tape }\end{array}$ \\
\hline 0 & $\begin{array}{l}1035- \\
1105\end{array}$ & $\begin{array}{l}\text { Creating a Shared Statement of Aging } \\
\text { As a large group, link the theme postings into } \\
\text { groups. Create a phrase/word to describe each } \\
\text { theme cluster. In } 2 \text { smaller groups, write a }\end{array}$ & $\begin{array}{l}\text { Big markers; more } \\
\text { bricks }\end{array}$ \\
\hline
\end{tabular}




\begin{tabular}{|l|l|l|l|}
\hline$\#$ & TIME & \multicolumn{1}{|c|}{ ACTIVITY } & \multicolumn{1}{|c|}{$\begin{array}{c}\text { REQUIRED } \\
\text { RESOURCES }\end{array}$} \\
\hline 7 & & $\begin{array}{l}1105- \\
1125\end{array}$ & $\begin{array}{l}\text { Sentence that states “Aging is..." using the themes. } \\
\text { Taking a Walk with the Statement } \\
\text { Take a walk with a partner to collect an artifact } \\
\text { Aging statement and the implications for your } \\
\text { clinical placement. }\end{array}$ \\
\hline 8 & $\begin{array}{l}1125- \\
1155\end{array}$ & $\begin{array}{l}\text { Creating a Mantra for Clinical } \\
\text { Share the artifacts collected and the implications } \\
\text { they represent. Reflecting on the implications, } \\
\text { develop a shared Mantra/Pledge for the clinical } \\
\text { placements that students will endeavor to honor. }\end{array}$ & $\begin{array}{l}\text { Flipchart paper; big } \\
\text { markers }\end{array}$ \\
\hline 9 & $\begin{array}{l}1155- \\
1205\end{array}$ & $\begin{array}{l}\text { Check-out } \\
\text { Liked least; liked most } \\
\text { Pick a color }\end{array}$ \\
\hline
\end{tabular}

\begin{tabular}{|l|l|}
\hline Descriptive Notes: & Reflective Notes: \\
\hline $\begin{array}{l}\text { Chronological account of } \\
\text { activities. }\end{array}$ & $\begin{array}{l}\text { Notes about the process, reflections on activities, and } \\
\text { summary conclusions about activities. Notes about } \\
\text { recorder experiences, hunches, and learnings. }\end{array}$ \\
\hline & \\
& \\
\hline
\end{tabular}




\section{Workshop 2: Setting A Course for Learning}

This workshop provides participants with the opportunities to:

1. Evaluate hopes and fears for long-term care placement - hopes realized/unfulfilled; fears materialized/mitigated

2. Create an artifact representing aging based on the long-term care placement experience

3. Develop a shared vison for gerontological nursing

\begin{tabular}{|c|c|l|l|}
\hline$\#$ & TIME & \multicolumn{1}{|c|}{ ACTIVITY } & REQUIRED RESOURCES \\
\hline 1 & $1000-$ & $\begin{array}{l}\text { Re-introduction to study and signing of } \\
\text { consents } \\
\text { Check in - what are you most looking } \\
\text { forward to for the holiday season? }\end{array}$ & Consent forms \\
\hline 2 & $1020-$ & $\begin{array}{l}\text { Students will share narratives of their long- } \\
\text { term care placement experience. They are } \\
\text { instructed to select from the hopes and } \\
\text { fears bricks those that resonate with their } \\
\text { experience. They may select a brick of a } \\
\text { hope that was realized or unfulfilled, or } \\
\text { they may select a fear that materialized or } \\
\text { was mitigated. Students are also given a } \\
\text { blob diagram and asked to circle the blob } \\
\text { that best represents the gestalt of their } \\
\text { experience in long-term care. Students are } \\
\text { then invited to share their narratives, } \\
\text { referring to the bricks and blobs in their } \\
\text { presentation. }\end{array}$ & $\begin{array}{l}\text { Brich } \\
\text { paper) with hopes and fears } \\
\text { from workshop 1 recorded } \\
\text { Blob diagrams (1 per } \\
\text { participant) }\end{array}$ \\
\hline 3 & $\begin{array}{l}\text { 1100- } \\
1140\end{array}$ & $\begin{array}{l}\text { Students are asked to translate elements of } \\
\text { their experiences into a graffiti board that } \\
\text { represents “aging" as was revealed in the } \\
\text { long-term care placement. Students will cut } \\
\text { and paste images and words from } \\
\text { magazines and post them on the graffiti } \\
\text { board. Surrounding the board will be } \\
\text { themes of aging identified in workshop 1. } \\
\text { Debriefing will focus on the continuity with } \\
\text { and disconnect from students' original } \\
\text { view of aging and the one they are left with } \\
\text { after the placement. } \\
\text { End this session with a song (Piece by Piece } \\
\text { by the Quartet re Alzheimer). }\end{array}$ & $\begin{array}{l}\text { Butcher paper roll } \\
\text { Magazines } \\
\text { Scissors } \\
\text { Glue } \\
\text { Bricks from aging exercise in } \\
\text { workshop 1 (themes recorded } \\
\text { on bricks) } \\
\text { Quartet CD and music player }\end{array}$ \\
\hline 4 & $\begin{array}{l}\text { Students are given the visioning } \\
\text { questionnaire regarding gerontological } \\
\text { nursing and asked to complete it in silence. } \\
\text { Their responses are then translated onto }\end{array}$ & $\begin{array}{l}\text { Visioning hand outs } \\
\text { Flip chart paper (7) with } \\
\text { vision stems (1/page) } \\
\text { Markers }\end{array}$ \\
\hline 1240 & & \\
\hline
\end{tabular}




\begin{tabular}{|l|l|l|l|}
\hline & & $\begin{array}{l}\text { flipcharts using post-its. Pairs of students } \\
\text { will work to theme the post-its and finalize } \\
\text { a shared vision. }\end{array}$ & $\begin{array}{l}\text { Post-its } \\
\text { Tape }\end{array}$ \\
\hline 5 & $\begin{array}{l}1240- \\
1300\end{array}$ & $\begin{array}{l}\text { Check out - one take away from the } \\
\text { workshop experience, expressed as a "stop, } \\
\text { start, and continue" in regards to teaching } \\
\text { student nurses }\end{array}$ & \\
\hline
\end{tabular}


Appendix E

Blob Diagram

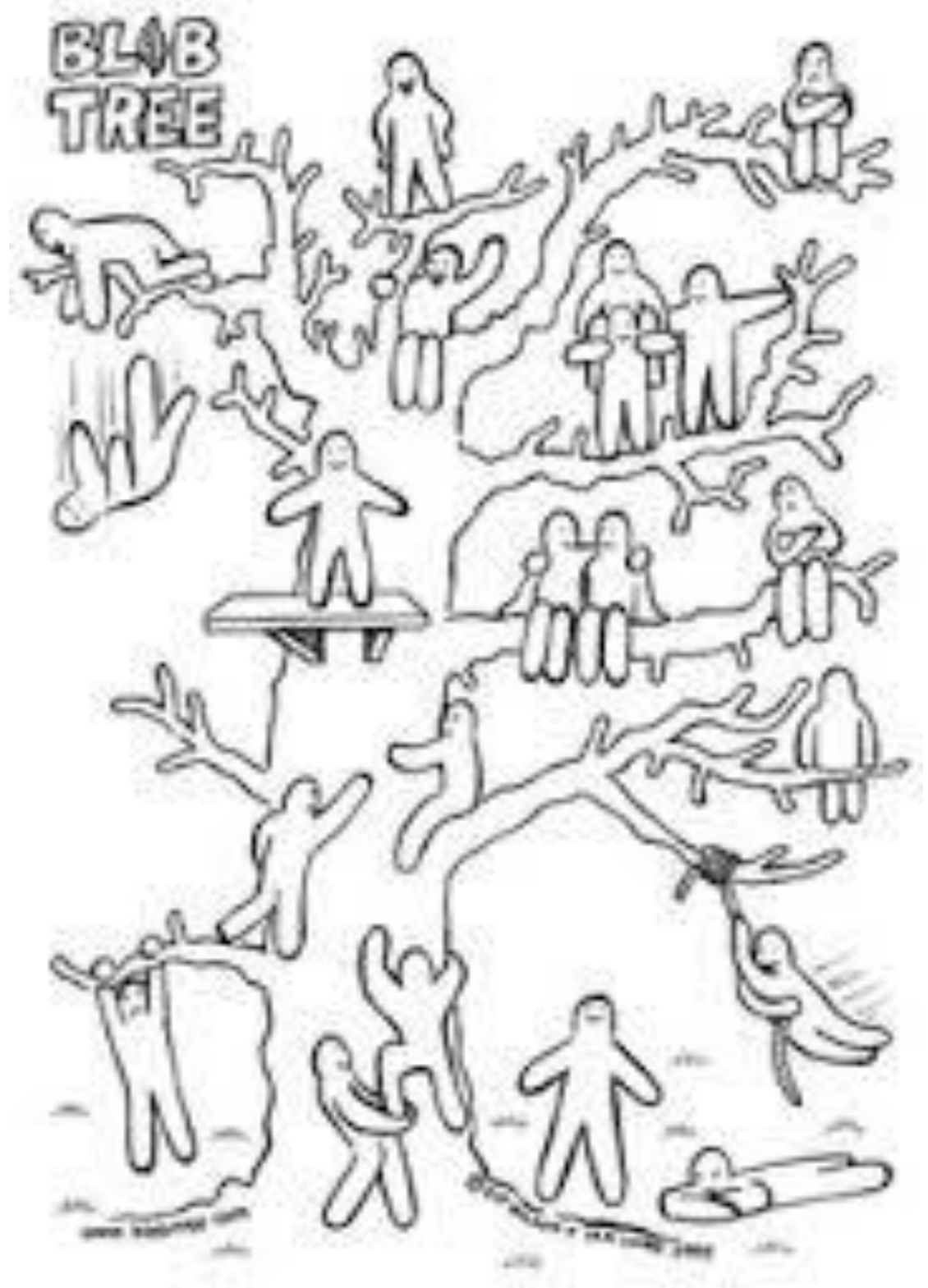

Credit: http://www.pipwilson.com/p/blob- 1 
Appendix F

Example of Data Analysis Process

\begin{tabular}{|c|r|r|}
\hline Sub-categories $\rightarrow$ & Generic Category $\rightarrow$ & Main Category \\
\hline Intention to support residents & Therapeutic Relationship with & \\
\hline residents & Residents & \multirow{2}{*}{ Relationships with Residents } \\
Intention to empower & Challenges in Building & \\
person-centred care & Relationships with Residents & \\
\cline { 1 - 2 } Difficulties communicating & & \\
\hline
\end{tabular}

(Elo \& Kyngäs, 2008) 


\section{References}

Abbey, J., Liddle, J., Bridges, P., Thornton, R., Lemcke, P., Elder, R., \& Abbey, B. (2006). Clinical placements in residential aged care facilities: The impact on nursing students' perception of aged care and the effect on career plans. The Australian Journal of Advanced Nursing, 23(4), 14-9.

Aday, R. H., \& Campbell, J. J. (1995). Changes in nursing students' attitudes and work preferences after a gerontology curriculum. Educational Gerontology, 21, 247-260.

Ayoğlu, F. N., Kulakçı, H., Ayyıldız, T. K., Aslan, G. K., \& Veren, F. (2014). Attitudes of turkish nursing and medical students toward elderly people. Journal of Transcultural Nursing, 25(3), 241-248. doi:10.1177/1043659613515527

Banning, M., Hill, Y., \& Rawlings, S. (2006). Student learning in care homes. Nursing Older People,17(10), 22-24.

Berntsen, K., \& Bjørk, I. T. (2010). Nursing students' perceptions of the clinical learning environment in nursing homes. The Journal of Nursing Education, 49(1), 17-22. doi:10.3928/01484834-20090828-06

Bleijenberg, N., Jansen, M., \& Schuurmans, M. (2012). Dutch nursing students' knowledge and attitudes toward older people-A longitudinal cohort study. Journal of Nursing Education and Practice, 2, 1-8.

Brown, J., Nolan, M., Davies, S., Nolan, J., Keady, J., 2008. Transforming students' views of gerontological nursing: Realising the potential of "enriched" environments of learning and care: a multi-method longitudinal study. International Journal of Nursing Studies, 45(8), 1214-1232. 
Brynildsen, G., Bjørk, I. T., Berntsen, K., \& Hestetun, M. (2014). Improving the quality of nursing students' clinical placements in nursing homes: An evaluation study. Nurse Education in Practice, 14(6), 722-728. doi:10.1016/j.nepr.2014.09.004

Burbank, P. M., Dowling-Castronovo, A., Crowther, M. R., \& Capezuti, E. A. (2006). Improving knowledge and attitudes toward older adults through innovative educational strategies. Journal of Professional Nursing, 22, 91-97.

Cammer, A., Morgan, D., Stewart, N., McGilton, K., Rycroft-Malone, J., Dopson, S., \& Estabrooks, C. (2013). The hidden complexity of long-term care: How context mediates knowledge translation and use of best practices. The Gerontologist, 54(6), 1013-1023. doi:10.1093/geront/gnt068

Carlson, E., Idvall, E. (2014). Nursing students' experiences of the clinical learning environment in nursing homes: A questionnaire study using the CLES+T evaluation scale. Nurse Education Today, 34(7), 1130-1134.

Celik, S. S., Kapucu, S., Tuna, Z., \& Akkus, Y. (2010). Views and attitudes of nursing students toward ageing and older patients. Australian Journal of Advanced Nursing, 27, 24-30.

Chan, D. S. (2002). Associations between student learning outcomes from their clinical placement and their perceptions of the social climate of the clinical learning environment. International Journal of Nursing Studies, 39, 517-524.

Chen, S., Brown, J. W., Groves, M. L., \& Spezia, A. M. (2007). Baccalaureate education and American nursing homes: A survey of nursing schools. Nurse Education Today, 27(8), 909-914. doi:10.1016/j.nedt.2007.01.004

Chickering, A. W. \& Gamson, Z. F. (1987) Seven Principles for Good Practice in Undergraduate Education. American Association of Higher Education Bulletin. 
College of Nurses of Ontario. (2014). Competencies for Entry-Level Registered Nurse Practice. Retrieved from https://www.cno.org/globalassets/docs/reg/41037_entrytopracitic_ final.pdf

Cozort, R. (2008). Student nurses' attitudes regarding older adults: Strategies for fostering improvement through academia. Teaching and Learning in Nursing, 3(1), 21-25.

Creswell, J. W. (2013). Qualitative inquiry and research design: Choosing among five approaches. $\left(3^{\text {rd }}\right.$ ed.). Thousand Oaks, CA: Sage.

Davies, S., Gell, L., Tetley, J., \& Aveyard, B. (2002). Learning to nurse in care homes: Student support. Nursing Standard, 17(13), 39-42.

De Guzman, A. B., Cruz, A. R., Cruz, A. G., Cruz, R. D., \& Cuarto, J. L. (2009). The Filipino nursing students' dilemmas in geriatric care. Educational Gerontology, 35(8), 673-686.

De Guzman, A. B., Dangoy, R. D., David, K. V., Dayo, K. H., de Claro, K. A., de Guzman, G. G., \& de Jesus, G. D. (2009). How many sides does a coin have? A phenomenology of Filipino nurses' motivation and attitudes toward geriatric care. Educational Gerontology, 35(3), 260-276.

De Guzman, A. B., Jimenez, B. C. B., Jocson, K. P., Junio, A. R., Junio, D. E., Jurado, J. B. N., \& Justiniano, A. B. F. (2013). Filipino nursing students' behavioral intentions toward geriatric care: A structural equation model (SEM). Educational Gerontology, 39 (3), 138.

Dewing, J. (2010). Moments of movement: Active learning and practice development. Nurse Education in Practice, 10(1), 22-26.

Duggan, S., Mitchell, E. A., \& Moore, K. D. (2013). 'With a bit of tweaking...we could be great': An exploratory study of the perceptions of students on working with older people 
in a preregistration BSc (Hons) Nursing course. International Journal of Older People Nursing, 8, 207- 215. doi:10.1111/j.1748-3743.2012.00317.x

Elo, S., \& Kyngäs, H. (2008). The qualitative content analysis process. Journal of Advanced Nursing, 62(1), 107-115.

Fagerberg, I., \& Ekman, S. (1997). First-year Swedish nursing students' experiences with elderly patients. Western Journal of Nursing Research, 19(2), 177-189. doi:10.1177/019394599701900204

Fagerberg, I., Winblad, B., \& Ekman, S. (2000). Influencing aspects in nursing education on Swedish nursing students' choices of first work area as graduated nurses. Journal of Nursing Education, 39, 211-128.

Fay, B. (1987) Critical social science. Cambridge: Polity Press.

Ferrario, C. G., Freeman, F. J., Nellett, G., \& Scheel, J. (2008). Changing nursing students' attitudes about aging: An argument for the successful aging paradigm. Educational Gerontology, 34, 51-66.

Flood, M. T., \& Clark, R. B. (2009). Exploring knowledge and attitudes toward aging among nursing and nonnursing students. Educational Gerontology, 35, 587-595.

Ford, J. S., \& Profetto-McGrath, J. (1994). A model for critical thinking within the context of curriculum as praxis. Journal of Nursing Education, 33, 341-344.

Fox, S. D., \& Wold, J. E. (1996). Baccalaureate student gerontological nursing experiences: Raising consciousness levels and affecting attitudes. The Journal of Nursing Education, 35(8), 348. 
Georges, A., Romme, L., \& van Witteloostuijn, A. (1999). Circular organizing and triple loop learning. Journal of Organizational Change Management, 12(5), 439-454. doi:10.1108/09534819910289110

Graneheim, U. H., \& Lundman, B. (2004). Qualitative content analysis in nursing research: Concepts, procedures and measures to achieve trustworthiness. Nurse Education Today, 24(2), 105-112.

Greenwood, J. (1998). The role of reflection in single and double loop learning. Journal of advanced nursing, 27(5), 1048-1053.

Guba, E. G., \& Lincoln, Y. S. (1981). Effective evaluation. San Francisco, CA: Joey-Bass. Happell, B. (2002). Nursing home employment for nursing students: Valuable experience or a harsh deterrent? Journal of Advanced Nursing, 39, 529--536.

Happell, B., \& Broker, J. (2001). Who will look after my grandmother? Attitudes of student nurses toward the care of older adults. Journal of Gerontological Nursing, 27, 12-17.

Haron, Y., Levy, S., Albagli, M., Rotstein, R., \& Riba, S. (2013). Why do nursing students not want to work in geriatric care? A national questionnaire survey. International Journal of Nursing Studies, 50(11), 1558-1565. doi:10.1016/j.jpurstu.2013.03.012

Hartley, C., Bentz, P. \& Ellis, J. (1995). The effect of early nursing home placement on students' attitudes toward the elderly. Journal of Nursing Education 34(3), 128-130.

Henderson, J., Xiao, L., Siegloff, L., Kelton, M., \& Paterson, J. (2008). ‘Older people have lived their lives': First year nursing students' attitudes towards older people. Contemporary Nurse, 30(1), 32-45.

Hweidi, I. M., \& Al-Obeisat, S. M. (2006). Jordanian nursing students' attitudes toward the elderly. Nurse Education Today, 26, 23-30. 
King, B. J., Roberts, T. J., \& Bowers, B. J. (2013). Nursing student attitudes toward and preferences for working with older adults. Gerontology \& Geriatrics Education, 34(3), 272-291. doi:10.1080/02701960.2012.718012

Kloster, T., Høie, M., \& Skår, R. (2007). Nursing students' career preferences: A Norwegian study. Journal of Advanced Nursing, 59, 155-162.

Koh, L.C. (2012). Student attitudes and educational support in caring for older people - a review of literature. Nurse Education in Practice, 12(1), 16-20.

Koren, M. E., Hertz, J., Munroe, D., Rossetti, J., Robertson, J., Plonczynski, D., Berent, G. \& Ehrlich-Jones, L. (2008). Assessing students' learning needs and attitudes: Considerations for gerontology curriculum planning. Gerontology \& Geriatrics Education, 28(4), 39-56. doi:10.1080/02701960801963029

Koskinen, S., Hupli, M., Katajisto, J., Salminel, L. (2012). Graduating Finnish nurse students' interest in gerontological nursing a survey study. Nurse Education Today, 32(4) 356-360.

Lambrinou, E., Sourtzi, P., Kalokerinou, A., \& Lemonidou, C. (2009). Attitudes and knowledge of the Greek nursing students toward older people. Nurse Education Today, 29, 617-622.

Lane, A. M., \& Hirst, S. P. (2012). Placement of undergraduate students in nursing homes: Careful consideration versus convenience. Journal of Nursing Education, 51(3), 145-149.

Larsen, J. A., Maundrill, R., Morgan, J., \& Mouland, L. (2005). Practice development facilitation: An integrated strategic and clinical approach. Practice Development in Health Care, 4(3), 142-149.

Lea, E., Marlow, A., Bramble, M., Andrews, S., Crisp, E., Eccleston, C., Mason, R. \& Robinson, A. (2014). Learning opportunities in a residential aged care facility: The role of supported 
placements for first-year nursing students. Journal of Nursing Education, 53(7), 410-414. doi:10.3928/01484834-20140620-02

Manley, K., \& McCormack, B. (2003). Practice development: Purpose, methodology, facilitation and evaluation. Nursing in Critical Care, 8(1), 22-29.

Mauro, A. M. P., Hickey, M. T., McCabe, D. E., \& Ea, E. (2012). Attaining baccalaureate competencies for nursing care of older adults through curriculum innovation. Nursing Education Perspectives, 33(3), 187-90.

McCann, T. V., Clark, E., \& Lu, S. (2010). Bachelor of nursing students career choices: A threeyear longitudinal study. Nurse Education Today, 30(1), 31-36.

McCleary, R. (2014). Using film and intergenerational colearning to enhance knowledge and attitudes toward older adults. Educational Gerontology, 40(6), 414-426. doi:10.1080/03601277.2013.844034

McCormack, B., Manley, K., \& Titchen, A. (Eds.). (2013). Practice development in nursing and healthcare. West Sussex: John Wiley \& Sons.

McCormack, B., \& Titchen, A. (2006). Critical creativity: Melding, exploding, blending. Educational Action Research, 14(2), 239-266.

McGarry, J., Aubeeluck, A., Simpson, C., \& Williams, G. (2009). Nursing students’ experience of care. Nursing Older People, 21(7) 16-22.

McKinlay, A., \& Cowan, S. (2003). Student nurses' attitudes toward working with older patients. Journal of Advanced Nursing, 43, 298-309.

Moyle, W. (2003). Nursing students' perceptions of older people: Continuing society's myths. The Australian Journal of Advanced Nursing, 20(4), 15-21. 
Ontario Association of Non-Profit Homes and Services for Seniors. (2012). Municipal Delivery of Long-Term Care Services: Understanding the Context and the Challenges. Retrieved from https://www.oanhss.org/oanhssdocs/Media_Centre/PositionPapers/Municipal_Brief _July_2012.pdf

Ontario Long Term Care Association. (2014). This is Long-Term Care 2014. Retrieved from http ://www.oltca.com/oltca/Documents/Reports/This_is_LongTerm_Care_2014_Final.pdf

Pan, I. J., Edwards, H., \& Chang, A. (2009). Taiwanese nursing students' attitudes toward older people. Journal of Gerontological Nursing, 25, 1-6.

Potter, P. A., Perry, A. G., Ross-Kerr, J. C., \& Wood, M. J. (Eds.). (2010). Canadian fundamentals of nursing (4th ed.). Toronto: Elsevier Canada.

Price, S. L. (2009). Becoming a nurse: A meta- study of early professional socialization and career choice in nursing. Journal of Advanced Nursing, 65(1), 11-19.

Reutter, L., Field, P. A., Campbell, I. E., \& Day, R. (1997). Socialization into nursing: Nursing students as learners. The Journal of Nursing Education, 36(4), 149.

Robinson, A., \& Cubit, K. (2005). Student nurses' experiences of the body in aged care. Contemporary Nurse, 19, 41-51.

Rogan, F., \& Wyllie, A. (2003). Engaging undergraduate nursing students in the care of elderly residents in australian nursing homes. Nurse Education in Practice, 3(2), 95-103. doi:10.1016/S1471-5953(02)00085-9

Royal College of Nursing (2007) Workplace Resources for Practice Development. London: Royal College of Nursing Institute. 
Ryan, M., \& McCauley, D. (2005). We built it and they did not come: Knowledge and attitudes of baccalaureate nursing students toward the elderly. Journal of New York State Nurses Association, 35(2), 5-9.

Ryan, A., Melby, V., \& Mitchell, L. (2007). An evaluation of the effectiveness of an educational and experiential intervention on nursing students' attitudes towards older people. International Journal of Older People Nursing, 2(2), 93-101. doi:10.1111/j.17483743.2007.00060.x

Saarikoski, M., \& Leino-Kilpi, H. (2002). The clinical learning and supervision by staff nurses: Developing the instrument. International Journal of Nursing Studies, 39 (3), 259-267. Saarikoski, M., Isoaho, H., Warne, T., \& Leino-Kilpi, H. (2008). The nurse teacher in clinical practice: Developing the new sub-dimension to the clinical learning environment and supervision (CLES) scale. International Journal of Nursing Studies 45 (8), 1233 1237.

Sandelowski, M. (1986). The problem of rigor in qualitative research. Advances in Nursing Science, 8(3), 27-37.

Sandelowski, M. (1991). Telling stories: Narrative approaches in qualitative research. Journal of Nursing Scholarship, 23(3), 161-166.

Sandelowski, M. (1993). Rigor or rigor mortis: The problem of rigor in qualitative research revisited. Advances in Nursing Science, 16(2), 1-8.

Sandelowski, M. (2000). Whatever happened to qualitative description? Research in Nursing \& Health, 23, 334-340.

Sandelowski, M. (2010). What's in a name? Qualitative description revisited. Research in Nursing \& Health, 33(1), 77-84. 
Scheffler, S. J. (1995). Do clinical experiences affect nursing students' attitudes toward the elderly? Journal of Nursing Education, 34, 312-316.

Sheffler, S. J. (1998). Clinical placement and correlates affecting student attitudes toward the elderly. Journal of Nursing Education, 37, 216-218.

Schön, D. (1983). The Reflective Practitioner. Temple Smith, London.

Shen, J., \& Xiao, L.D. (2012). Factors affecting nursing students' intention to work with older people in China. Nurse Education Today 32(3) 219-223.

Silversides, A. (2011). Long-term care in Canada: Status quo no option (1st ed.) Canadian Federation of Nurses Unions.

Simmons, M. (2004). 'Facilitation' of practice development: A concept analysis. Practice Development in Health Care 3(1): 36-52.

Skaalvik, M. W., Normann, H. K., \& Henriksen, N. (2010). Student experiences in learning person-centred care of patients with Alzheimer's disease as perceived by nursing students and supervising nurses. Journal of Clinical Nursing, 19 (17-18), 2639. doi:10.1111/j.1365-2702.2010.03190.x

Skaalvik, M. W., Normann, K., \& Henriksen, N. (2012). Nursing homes as learning environments: The impact of professional dialogue. Nurse Education Today, 32(4), 412416. doi:10.1016/j.nedt.2011.03.001

Soderhamn, O., Lindencrona, C., \& Gustavsson, S. M. (2001). Attitudes toward older people among nursing students and registered nurses in Sweden. Nurse Education Today, 21, 225-229.

Statistics Canada (2011). Indicators of well-being in canada: Canadians in context-aging population. Retrieved from http://www4.hrsdc.gc.ca/.3ndic.1t.4r@-eng.jsp?iid=33 
Stevens, J. A. (2011). Student nurses' career preferences for working with older people: A replicated longitudinal survey. International Journal of Nursing Studies 48, 944-951.

Streubert, H. J., \& Carpenter, D. R. (2013). Qualitative research in nursing: Advancing the humanistic imperative. $\left(6^{\text {th }}\right.$ ed.). Philadelphia: Lippincott, Williams \& Wilkins.

Thorne, S. E. (1991). Methodological orthodoxy in qualitative nursing research: Analysis of the issues. Qualitative Health Research, 1(2), 178-199. doi:10.1177/104973239100100203

Thorne, S., Kirkham, S. R., \& MacDonald-Emes, J. (1997). Interpretive description: A noncategorical qualitative alternative for developing nursing knowledge. Research in Nursing \& Health, 20(2), 169-177.

Titchen, A. (2003). Critical companionship: Part 1. Nursing Standard, 18(9), 33-40.

Titchen, A., \& McCormack, B. (2010). Dancing with stones: Critical creativity as methodology for human flourishing. Educational Action Research, 18(4), 531-554.

United Nations, Department of Economic and Social Affairs, Population Division (2013). World Population Ageing 2013. ST/ESA/SER.A/348.

Vaismoradi, M., Turunen, H., \& Bondas, T. (2013). Content analysis and thematic analysis:

Implications for conducting a qualitative descriptive study. Nursing and Health Sciences, 15(3), 398-405.

Wade, S., \& Skinner, A. (2001). Student placements in nursing homes. Nursing Older People, 13(2), 14.

Warfield, C. \& Manley, K. (1990). Developing a new philosophy in the NDU. Nursing Standard, 4(41), 27-30.

Wesley, S. (2005). Enticing students to careers in gerontology: Faculty and student perspectives. Gerontology \& Geriatrics Education, 25(3), 13-29. 
Williams, B., Anderson, M. C., \& Day, R. (2007). Undergraduate nursing students' knowledge of and attitudes toward aging: Comparison of context-based learning and a traditional program. Journal of Nursing Education, 46, 115-120.

Williams, K. N., Nowak, J., \& Scobee, R. L. (2006). Fostering student interest in geriatric nursing: Impact of senior long-term care experiences. Nursing Education Perspectives, 27, 190-193.

Wright, J., \& Titchen, A. (2003). Critical companionship part 2: Using the framework. Nursing Standard, 18(10), 33 .

Zambrini, D. A. B., Moraru, M., Hanna, M., Kalache, A., \& Nuñez, J. F. M. (2008). Attitudes toward the elderly among students of health care related studies at the University of Salamanca, Spain. Journal of Continuing Education in the Health Professions, 28, 86-90.

Zisberg, A., Topaz, M., \& Band-Wintershtein, T. (2014). Cultural- and educational-level differences in students knowledge, attitudes, and preferences for working with older adults: An Israeli perspective. Journal of Transcultural Nursing, 26(2), 193-201. doi:10.1177/1043659614526252

Zverev, Y. (2013). Attitude towards older people among Malawian medical and nursing students. Educational Gerontology, 39(1), 57. doi:10.1080/03601277.2012.660869 
